\title{
MODELING OF SYNCHRONOUS GENERATOR AND FULL-SCALE CONVERTER FOR DISTRIBUTION SYSTEM LOAD FLOW ANALYSIS
}

\author{
by \\ Inderpreet Singh Wander \\ Master of Technology, Electrical Engineering, P. A. University, India, 2000
}

\author{
A thesis \\ presented to Ryerson University \\ in partial fulfillment of the \\ requirements for the degree of \\ Master of Applied Science \\ in the program of \\ Electrical and Computer Engineering
}

Toronto, Ontario, Canada, 2011

(C) Inderpreet Singh Wander 2011 


\section{AUTHOR'S DECLARATION}

I hereby declare that I am the sole author of this thesis or dissertation.

I authorize Ryerson University to lend this thesis or dissertation to other institutions or individuals for the purpose of scholarly research.

(Inderpreet Singh Wander)

I further authorize Ryerson University to reproduce this thesis or dissertation by photocopying or by other means, in total or in part, at the request of other institutions or individuals for the purpose of scholarly research.

(Inderpreet Singh Wander) 


\title{
ABSTRACT \\ MODELING OF SYNCHRONOUS GENERATOR AND FULL-SCALE CONVERTER FOR DISTRIBUTION SYSTEM LOAD FLOW ANALYSIS
}

\author{
Inderpreet Singh Wander \\ Masters of Applied Science, Electrical and Computer Engineering, Ryerson University, 2011
}

Environmental awareness and the need to reduce greenhouse gas emissions have promoted the use of green energy sources such as Wind Energy Conversion Systems (WECS). The Type 4 Permanent Magnet Synchronous Generator (PMSG) with a Full-Scale Converter has grown to be a preferred choice among WECS. Conventionally these WECS are modeled as fixed PQ injections in distribution system analysis studies and for that reason they are not accurately represented. This inaccuracy is accentuated given the large-scale of integration of WECS. To overcome this limitation, this thesis proposes to develop a steady-state model for the Type 4 PMSG WECS to be used in unbalanced three-phase distribution load flow programs. The proposed model is derived from the analytical representation of its six main components: (1) the wind turbine, (2) the synchronous generator, (3) the diode-bridge rectifier, (4) voltage source inverter, (5) the dc-link with a boost converter that connects them, and (6) control mode action. This proposed model is validated through mathematical analysis and by comparing with a Matlab/Simulink model. Subsequently, the proposed model is integrated into a three-phase unbalanced load flow program. The IEEE 37-bus test system data is used to benchmark the results of the power flow method. 


\section{ACKNOWLEDGMENTS}

I express my deepest gratitude and appreciation to my supervisors, Dr. Bala Venkatesh of Ryerson University and Dr. Vijay K. Sood of UOIT for their continuous guidance, enlightenment, valuable instruction, encouragement and exceptional support throughout the period of this research and Masters degree.

I gratefully acknowledge the financial support by the NSERC grant to Dr. Bala Venkatesh and Dr. Vijay K. Sood.

My special thanks go to Dr. Alexandre Nassif, Post Doctoral Fellow at Ryerson University for providing his valuable suggestion in improvement of this thesis.

I would like to express my thankfulness to faculty members and staff of Electrical and Computer Engineering department of Ryerson University.

I will always remember all my friends in the Power and Energy Analysis Research Laboratory, especially Amit, Bhanu, Inderdeep and Syed for the technical conversations, exchange of ideas and moral support during my study at Ryerson University

I also thank my family and friends for their support and encouragement.

My deepest gratitude goes to my parents who have always provided unconditional support. Thanks also go to my sister and brother-in-law.

Last but not least, my special thanks to my wife and two lovely kids for their love and encouragement which has enabled me to complete this thesis. 


\section{TABLE OF CONTENT}

Chapter Title $\quad$ Page

$\begin{array}{ll}\text { Title Page } & \text { i }\end{array}$

Author's Declaration $\quad$ iii

Abstract $\quad$ iv

$\begin{array}{ll}\text { Acknowledgement } & \text { v }\end{array}$

Table of Content vi

List of Tables $\quad$ ix

List of Figures $\quad x$

List of Abbreviations $\quad$ xi

Nomenclature $\quad$ xiii

$\begin{array}{ll}\text { 1. Introduction } & 1\end{array}$

$\begin{array}{lll}1.1 & \text { Background } & 1\end{array}$

1.2 Review of Related Research 3

1.3 Objective and Contributions of this Research and Thesis Outline 5

$\begin{array}{lll}\text { 2. Wind Energy Systems } & 7\end{array}$

$\begin{array}{lll}2.1 & \text { Wind Energy Conversion Systems } & 7\end{array}$

$\begin{array}{lll}2.2 & \text { Classification } & 8\end{array}$

2.2.1 Aerodynamic Power Control 8

2.2.2 Speed Control 9

2.2.2.1 Fixed-speed WECS 9

$\begin{array}{ll}\text { 2.2.2.2 Variable-speed WECS } & 10\end{array}$

2.3 Synchronous Generator and Full-Scale Converter WECS 13

2.3.1 Structure 13

$\begin{array}{ll}\text { 2.3.2 Operation } & 14\end{array}$ 
$\begin{array}{lll}3.1 & \text { Model } & 16\end{array}$

$\begin{array}{ll}\text { 3.1.1 Wind Turbine Model } & 17\end{array}$

$\begin{array}{lll}\text { 3.1.2 Synchronous Generator Model } & 17\end{array}$

3.1.3 Three Phase Diode Bridge Rectifier Model 18

$\begin{array}{lll}3.1 .4 & \text { Boost Converter Model } & 19\end{array}$

3.1.5 Voltage Source Inverter 20

3.1.6 Control Mode Action 20

3.1.7 Proposed Complete Type 4 Generator Model Algorithm 20

$\begin{array}{lll}3.2 & \text { Validation } & 20\end{array}$

4. New Load Flow approach with the Proposed Type 4 WECS Model 24

4.1 Load Flow Method Description 24

4.2 Test System Description $\quad 29$

4.3 WECS Model in Load flow Analysis - Two Approaches 31

4.3.1 Conventional Load Flow Approach with the Conventional Type 4 WECS

Model (LF-1) 32

4.3.2 New Load Flow Approach with the Proposed Type 4 WECS Model (LF-2) 32

4.3.3 Results and Comparisons of Power Flow Methods 33

5. Conclusions and Suggestions for Future Research 37

$\begin{array}{lll}5.1 & \text { Conclusions } & 37\end{array}$

5.2 Suggestions for Future Research 38

References $\quad 39$

$\begin{array}{ll}\text { Appendices } & \mathbf{4 0}\end{array}$

Appendix A: Data Set for the Type 4 PMSG WECS Model 43

Appendix B: Load Models Description with General Equations 44

Appendix C: Computation of a, b, c, d, A, B Parameters of Series Feeder Components 46 
Appendix D: MATLAB Code for Load Flow

Appendix E: MATLAB Code for Proposed Type 4 Model 


\section{LIST OF TABLES}

Table 3.1: Results from both models for the Type 4 WECS

Table 4.1: Comparison of results from both Load Flow methods for the IEEE 37-bus test system

Table 4.2: Comparison of voltages and powers at the bus connecting the WECS for both Load Flow methods

Table A.1: Wind Turbine data set

Table A.2: Generator data set 43

Table A.3: Converter data set 


\section{LIST OF FIGURES}

Figure 2.1: A generic Wind Energy Conversion System $\quad 7$

Figure 2.2: Synchronous generator and full-scale converter WECS 13

Figure 3.1: Proposed equivalent model for the Type 4 WECS 16

Figure 3.2: Type 4 WECS model in Matlab-Simulink 22

Figure 4.1: Flowchart of Load Flow using conventional Ladder Iterative Technique 26

Figure 4.2: WECS connection to the IEEE 37-bus test system 30

Figure 4.3: Flowchart of Load Flow with Ladder Iterative Technique 31

Figure 4.4: WECS modeled as a fixed PQ load 32

Figure 4.5: Proposed WECS model integrated in the Load Flow solution 33

Figure 4.6: Comparison of line to line voltage a-b for both Load Flow approaches 35

Figure B.1: Delta connected load 44 


\section{LIST OF ABBREVIATIONS}

$\mathrm{AC}$

CanWEA

DC

DFIG

DG

DS

ERR

EMF

GW

GWEC

GSC

HAWT

IEEE

IGBT

IT

KCL

KVA

KVL

LF

MW

NSC

PE

PMSG

PWM

TOL

TS

VAWT

VSC
Alternating current

Canadian Wind Energy Association

Direct Current

Doubly Fed Induction Generator

Distributed Generation

Distribution System

Error Value

Electromotive Force

Giga Watts

Global Wind Energy Council

Generator- Side Converter

Horizontal Axis Wind Turbine

Institute of Electrical and Electronics Engineers

Insulated Gate Bi-polar Junction Transistor

Iteration Number

Kirchhoff Current Law

Kilo Volt Ampere

Kirchhoff Voltage Law

Load Flow

Mega Watts

Network- Side Converter

Power Electronics

Permanent Magnet Synchronous Generator

Pulse Width Modulation

Tolerance

Transmission System

Vertical Axis Wind Turbine

Voltage Source Converter 
VSI

WECS

WEG

WF

WG

WT

WRIG

WRSG

SG
Voltage Source Inverter

Wind Energy Conversion Systems

Wind Electric Generator

Wind Farm

Wind Generator

Wind Turbine

Wound Rotor Induction Generator

Wound Rotor Synchronous Generator

Synchronous Generator 


\section{NOMENCLATURE}

\begin{tabular}{|c|c|}
\hline A & Swept area of the rotor $\left(\mathrm{m}^{2}\right)$ \\
\hline$\beta$ & Blade pitch angle $\left(^{\circ}\right)$ \\
\hline $\mathrm{C}_{\mathrm{p}}$ & Power coefficient \\
\hline$\omega_{\text {wind }}$ & Wind speed $(\mathrm{m} / \mathrm{s})$ \\
\hline$\rho$ & Air density $\left(\mathrm{kg} / \mathrm{m}^{3}\right)$ \\
\hline $\mathrm{P}_{\text {Wind }}$ & Power available in wind (W) \\
\hline $\mathrm{P}_{\mathrm{m}}$ & Mechanical power developed by the wind turbine (W) \\
\hline$\lambda$ & Tip speed ratio \\
\hline $\mathrm{f}$ & Frequency $(\mathrm{Hz})$ \\
\hline $\mathrm{N}$ & Number of coil turns \\
\hline$\omega_{\mathrm{e}}$ & Electrical speed (radians/s) \\
\hline$\omega_{\mathrm{m}}$ & Mechanical speed(radians/s) \\
\hline $\mathrm{p}$ & Number of pairs of poles of the synchronous generator \\
\hline $\mathrm{R}_{\mathrm{s}}$ & Generator winding resistance $(\Omega)$ \\
\hline $\mathrm{X}_{\mathrm{s}}$ & Generator winding reactance $(\Omega)$ \\
\hline$\overline{\mathrm{E}}_{\mathrm{ph}}$ & Induced electromotive force $(\mathrm{V})$ \\
\hline$\overline{\mathrm{I}}_{\mathrm{s} \_\mathrm{ph}}$ & Generator current in phase ph (A) \\
\hline$\phi$ & Generator magnetic flux (Wb) \\
\hline$\varphi_{\mathrm{t} \_\mathrm{ph}}$ & Generator voltage phase angle \\
\hline$\theta_{\mathrm{s} \_\mathrm{ph}}$ & Generator current phase angle \\
\hline$\overline{\mathrm{V}}_{\mathrm{t} \_\mathrm{ph}}$ & Generator terminal voltage of phase ph (V) \\
\hline $\mathrm{V}_{\mathrm{LL}}$ & Generator line-to-line output voltage (V) \\
\hline
\end{tabular}




\begin{tabular}{|c|c|}
\hline $\mathrm{V}_{\mathrm{dcr}}$ & Rectifier output DC voltage (V) \\
\hline $\mathrm{I}_{\mathrm{dcr}}$ & Rectifier output DC current (A) \\
\hline $\mathrm{I}_{\mathrm{S} 1}$ & Fundamental component of the generator stator current (A) \\
\hline $\mathrm{P}_{\mathrm{dci}}$ & DC power flowing out of rectifier $(\mathrm{W})$ \\
\hline $\mathrm{R}_{\mathrm{r}}$ & $\operatorname{Rectifier} \operatorname{losses}(\Omega)$ \\
\hline $\mathrm{V}_{\mathrm{dcb}}$ & DC voltage across the boost converter (V) \\
\hline$V_{\text {dca }}$ & DC voltage output at the boost converter (V) \\
\hline $\mathrm{D}$ & Boost converter duty cycle \\
\hline $\mathrm{I}_{\mathrm{dcb}}$ & DC current output from the boost converter (A) \\
\hline $\mathrm{P}_{\mathrm{dcb}}$ & DC power output from the boost converter (W) \\
\hline $\mathrm{R}_{\mathrm{b}}$ & Boost converter losses $(\Omega)$ \\
\hline$V_{\text {a_ph }}$ & Phase voltage at the VSI terminal (V) \\
\hline $\mathrm{m}_{\mathrm{a}}$ & VSI PWM modulation index \\
\hline $\mathrm{V}_{\mathrm{o} \_\mathrm{ph}}$ & Three-phase VSI output voltage (V) \\
\hline$\varphi_{\mathrm{o}_{-} \mathrm{ph}}$ & Angle of each VSI output phase voltage \\
\hline$\theta_{\mathrm{O} \_\mathrm{ph}}$ & Angle of each VSI output phase current \\
\hline $\mathrm{R}_{\mathrm{o}}$ & VSI output resistance including losses $(\Omega)$ \\
\hline$X_{0}$ & VSI output reactance $(\Omega)$ \\
\hline $\mathrm{P}_{\mathrm{O} \_\mathrm{ph}}$ & VSI phase real power output (W) \\
\hline$Q_{\text {o_ph }}$ & VSI phase reactive power output (Var) \\
\hline
\end{tabular}




\section{Chapter 1 \\ Introduction}

\subsection{Background}

The deregulation of electric markets has led to the emergence of distributed generation (DG). These units comprise renewable and non-renewable sources. With the increased awareness for environmental preservation and the drive to reduce greenhouse gas emissions, there has been a significant shift towards renewable energy sources, leading most people to associate the acronym DG with such. Among those, wind energy, being clean and commercially competitive, has been one of the most popular choices. A large number of Wind Energy Conversion Systems (WECS) are already in operation and many new systems are being planned [1]-[3]. According to the Global Wind Energy Council (GWEC), the total capacity of wind power operating in the world reached 194.4 GW in 2010, an increase of $22.5 \%$ from $159.2 \mathrm{GW}$ in 2009 [4]. In Canada alone, the installed capacity is $4009 \mathrm{MW}$ in 2010, an increase of 17\% from 2009 [5]. With many government incentives across most of its provinces, it is expected that wind power installation will experience steady growth in the forthcoming years.

Wind power conversion differs from other conventional sources due to (1) the construction of WECS, which most commonly use power electronics-based converters, resulting in the application of different topologies, (2) the unpredictable nature of wind power, which is intermittent and uncertain, and (3) the change from a passive distribution network into an active one with multiple energy sources and bidirectional power flow ${ }^{1}$. Due to these factors associated with wind power, it interacts differently with the power system network. The most obvious challenge that it can create is the dependence of the injected power on the wind speed. Therefore, fluctuations in wind velocity can affect branch power flows, bus voltages, reactive power injections, system balancing, frequency control, power system dynamics and stability. In addition, it can also affect the power quality by introducing harmonics and flicker, due to the

\footnotetext{
${ }^{1}$ Note that the reverse flow of power is not unique to wind energy conversion, but can take place in any scenario where DGs are connected to distribution feeders.
} 
switching actions of the power electronics converters, and can also affect protection systems due to the increase in fault levels [1]-[2].

Due to the aforementioned, different grid codes have been developed for wind power integration so as to fulfill technical requirements such as frequency and voltage control, active and reactive power management and fast response during transient and dynamic situations. To satisfy these requirements and because of other technical and economical reasons, different topologies of WECS have been developed. Variable-speed WECS are the favoured option due to superior power extraction, controllable output power, quick response under transient and dynamic situations, reduced mechanical stress and acoustical noise [1], [6], [7]. Variable-speed WECS can apply Doubly-Fed Induction Generators (DFIGs or Type 3 generators) or synchronous generators and full-scale converters (also referred to as Type 4 generators). While DFIGs have gained popularity in recent years, Type 4 generators have been gradually capturing the market [8]. More details on different WECS types are provided in Chapter 2.

Thus, electrical power systems are undergoing a change from a well-known and developed topology to another new and partly unknown. The interaction of wind turbines with electrical power systems is becoming more significant. With the rapid increase in the number of WECS in power system, the effects of wind power on the grid need to be fully understood and properly investigated. The steady-state investigation is done through Load Flow analysis, which is an important tool in power system planning and operation. The objective of a load flow is to determine the current flows on transmission lines (or distribution feeders) and transformers, voltages on buses and to calculate power line losses [14]-[15]. This study is also important in the planning and design of the interconnection of the wind farm to the system, to ensure that existing scenarios are operated within their capabilities and new scenarios (after the installation of WECS) are properly planned. The load flow is also commonly used to provide initial conditions for dynamic and stability analyses.

To obtain accurate results in the load flow analysis and adequately investigate their effects on the electric system, the detailed features of WECS must be included in the load flow algorithms. Ideally, this integration should not impact the performance of the solution algorithm. 


\subsection{Review of Related Research}

With the growth of wind power in power systems, a large number of studies have been done to investigate its behaviour and impact on the power system. Most of these studies are performed to investigate the dynamic behaviour. Conversely, very few studies have been done to understand the steady-state behaviour of wind turbines

In [11], comprehensive dynamic simulation models were implemented and advanced control strategies were designed for different wind turbine concept which were claimed to improve power system stability. The authors, in [12], have described the dynamic modelling and control system of a direct-drive wind turbine which enabled the wind turbine to operate optimally. In [13], converter driven synchronous generator models of various orders, which can be used for simulating transients and dynamics in a very wide time range, were presented.

The power output of the wind generator depends on the characteristics of the turbine and control systems. One of the important functions of the control systems is to determine the active and reactive powers supplied by the wind turbine to the grid. Conversely, the performance of the WECS is affected by the varying grid conditions. These conditions need to be considered when developing steady-state models for WECS.

A previous number of studies have modeled WECS as a simple induction generator equivalent circuit with very simple turbine characteristics [16]-[18]. In [16], two single-phase steady-state models of asynchronous generators were presented. One is a constant PQ model, in which active power is a function of wind speed. The other is a RX model, in which active and reactive powers are calculated by using equivalent circuit parameters of induction machine. This is claimed to be more accurate, with the advantage that the only input variable needed was the wind speed. The authors of [17] have compared two models of induction generator. One is a fixed PQ model whose reactive power is expressed as a function of WECS's mechanical input. The other is a fixed RX model, in which active and reactive power were calculated by using equivalent circuit parameter. The developed models were incorporated into three-phase distribution system load flow. A new approximate fixed PQ model of Asynchronous wind 
turbine was described in [18], in which mechanical power is the input variable and the reactive power is calculated as a function of the machine parameters and the voltage of the machine.

The authors of [19] have proposed steady-state models for the Doubly Fed Induction Generator (DFIG). These models ranged from a fixed PQ injection modeling approach to a more detailed level of modeling. The DFIG is also modeled as fixed PV or RX model. In the RX fixed model the wind speed was considered as input data, making the mechanical power as a function of given wind data. The study was limited to a single-phase model and a load flow solution based on the Newton-Raphson method.

As far as the Type 4 WECS is concerned, this WECS has been traditionally modeled by utilities as a constant PQ or PV bus [20], [22], [24-[25]. In some cases it was modeled as a single-phase system [21], [25] or as a three-phase balanced system [20]-[24].

In [20] and [24] different configurations were modeled as constant PQ and PV model, depending on the control used, for balanced three-phase load flow analysis. Various components of WECS were not considered in the models. In [21], steady-state models of different configurations of WECS were developed for single-phase load flow. These were modeled as fixed PQ and PV bus. Direct-Drive Synchronous Generator is then modelled as a PV bus in the load flow study. With reactive power limits enforced, if the limit is reached, the PV bus is converted to a PQ bus. These models do not consider the various components of whole WECS. Different models of various DGs, including different configurations of Wind Turbines, were developed in [22], with the claim that the traditional three-phase load low method was improved. But details have not been provided. Another modeling variant was presented in [23]. In these steady-state models of various types of WECS, the WECS components and losses have been ignored. Single-phase models were developed in [25] for different configurations of WECS to be used in the Newton-Raphson method-based load flow analysis. Variable-speed WTs were modeled as constant PQ model. Therefore this technique also lacks modeling accuracy. In addition, details of the asynchronous generator model is provided and not in the case of synchronous generator. 
While such approaches were considered reasonable to represent a few generators under balanced conditions, nowadays they are clearly inadequate to represent the Type 4 WECS given the present and anticipated scale of penetration in distribution systems. Therefore, with the noticeable acceptance of the Type 4 WECS by the market, it is visibly necessary to develop a more accurate model to represent the technology in load flow studies.

\subsection{Objective and Contribution of this Research and Thesis Outline}

Despite the growing scale of integration of the Type 4 WECS, very little research has been done towards developing an accurate model for distribution system planning and analysis studies. Most of the WECS units are being connected in distribution networks, which are usually unbalanced. Thus, with the anticipated large scale installation of Type 4 WECS, its accurate modelling has become very important.

The main objective of this thesis is to propose a three-phase model for Type 4 WECS representing all its components. The proposed model is validated by using Matlab-Simulink and subsequently incorporated in a three-phase load flow program used to solve the IEEE 37-bus unbalanced distribution system [39].

The main contributions of this research are those presented in Chapters 3 and 4.

The structure of this thesis is as follows:

Chapter 2 provides a background on wind energy conversion system along with their power controls. A detailed analysis of the Type 4 topology is presented.

Chapter 3 presents the modeling of all WECS elements and the proposed algorithm to obtain its complete model. This model is validated through time-domain simulations in Matlab-Simulink.

Chapter 4 presents the Load Flow solution using the ladder iterative technique with the integration of both (1) the traditional WECS model, and (2) the proposed WECS model with the 
IEEE-37 bus distribution system. Finally the resulting errors from using the traditional WECS model are quantified by comparing the results from both models.

Chapter 5 presents the conclusions and contributions of this thesis, as well as suggestions for future work. 


\section{Chapter 2 \\ Wind Energy Conversion Systems}

\subsection{Wind Energy Conversion Systems}

Figure 2.1 presents the topology of a complete wind energy conversion system (WECS) [1], [6], [26].

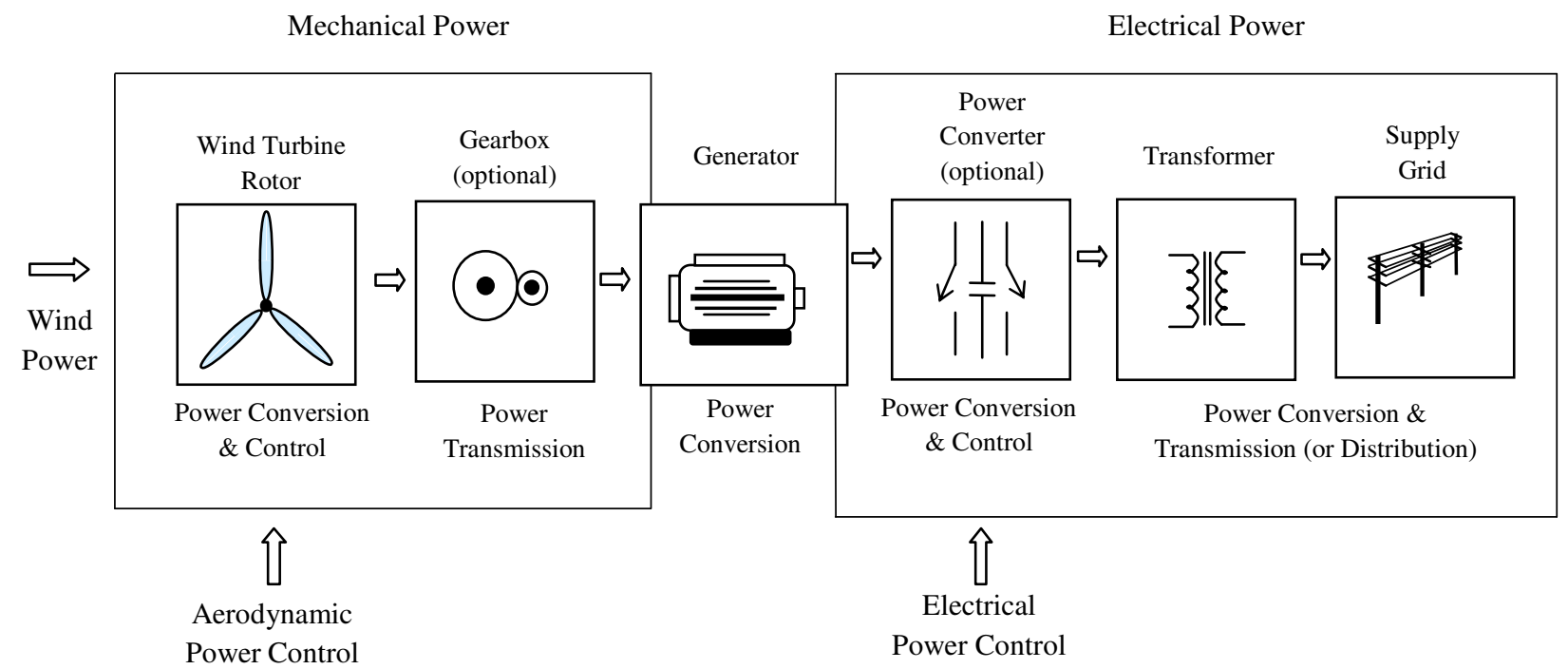

Figure 2.1: A generic Wind Energy Conversion System

WECS produce electricity by using the power of wind to drive an electrical generator. The conversion of the kinetic energy of the incoming air stream into the electrical energy takes place in two steps: the extraction device, i.e., the wind turbine rotor captures the wind power movement by means of aerodynamically designed blades, and converts it into rotating mechanical energy, which drives the generator rotor. The electrical generator then converts this rotating mechanical power into electrical power. A gear box may be used to match the rotational speed of the wind turbine rotor with one that is appropriate for the generator. The electrical power is then transferred to the grid through a transformer. The connection of the wind turbine to the grid is possible at different levels of voltage, with a common level being 600-700 V. Power electronics converters can also be used for enhanced power extraction and variable speed operation of the wind turbine. 


\subsection{Classification}

The development of various WECS concepts in the last decade has been very dynamic and several new configurations have been developed. With the development of power converter technologies, several different types of wind turbine configurations, using a wide variety of electric generators, are available. One difference in the basic configuration is the vertical axis wind turbine (VAWT) and horizontal axis wind turbine (HAWT). Today, the vast majority of manufactured wind turbines apply the horizontal axis. Another major difference among WECS concepts is the electrical design and control. So the WECS can be classified according to the speed control ability, leading to WECS classes differentiated by generator speed, and according to the power control ability, leading to WECS classes differentiated by the method employed for limiting the aerodynamic efficiency above rated power. Input wind power control ability divides WECS into three categories: Stall-controlled, Pitch-controlled, and Active-pitch controlled. The speed control criterion leads to two types of WECS: Fixed-speed and Variable-speed [1], [6], [26]. This chapter addresses most of the topologies widely in use today.

\subsubsection{Aerodynamic Power Control}

Power control ability refers to the aerodynamic performance of wind turbines. There are different ways to control aerodynamic forces on the turbine rotor and thus to limit the power in very high winds in order to avoid the damage to the wind turbine [1], [6], [26].

\section{Passive Stall control}

Input wind power is regulated by the aerodynamic design of the rotor blades. In this design, the blades are fixed to the hub at a fixed angle. This design causes the rotor to stall (lose power) when the wind speed exceeds a certain level. Thus, the aerodynamic power on the blades is limited. This method is simple, inexpensive, and mostly used in fixed-speed WECS. This arrangement causes less power fluctuations than a fast-pitch power regulation. On the negative side, this method has lower efficiency at low wind speeds and has no assisted start-up. 


\section{Pitch control (Active control)}

Input wind power is controlled by feathering the blades. In this method, blades are turned out or into the wind as the power output becomes too high or too low, respectively. Rotor blade pitch is varied to control both the rotational speed and the coefficient of performance. At high wind speeds the mean value of the power output is kept close to the rated power of the generator. Thus, power is controlled by modifying the pitch-angle, which modifies the way the wind speed is seen by the blade. This method has the advantages of good power control, assisted start-up and emergency stop. This is the most commonly used in variable-speed wind turbines. But his method suffers from extra complexity and higher power fluctuations at high wind speeds.

\section{Active stall control}

In this control method, the stall of the blade is actively controlled by pitching the blades. The blade angle is adjusted in order to create stall along the blades. At low wind speeds the blades are pitched similarly to a pitch-controlled wind turbine, in order to achieve maximum extraction from the wind. At high wind speeds, i.e., above rated wind speeds, the blades go into a deeper stall by being pitched slightly into the opposite direction to that of a pitch-controlled turbine. Smoother limited power is achieved without high power fluctuations as in the case of pitch-controlled wind turbines. This control type also compensates variations in air density. The combination with pitch mechanism makes it easier to carry out emergency stops and to start up the wind turbine.

\section{Yaw control}

Another control method is called the Yaw control, in which the entire nacelle is rotated around the tower to yaw the rotor out of the wind. Due to its complexity, the Yaw control is less utilized than other methods.

\subsubsection{Speed Control}

\subsubsection{Fixed-speed WECS (the Type 1 WECS)}

Fixed-speed WECS are electrically simple devices, consisting of an aerodynamic rotor driving an Induction (Squirrel cage or wound rotor) generator which is directly connected 
through gearbox and shaft. The slip, and hence the rotor speed of generator, varies with the amount of power generated. These rotor speed variations are, however, very small (approximately 1 to 2 percent). Therefore, this WECS is normally referred to as a constant or fixed speed system. The rotor speed is determined by the frequency of the supply grid, the gear ratio and the number of pole-pairs of a generator, regardless of the wind speed. These are designed to achieve maximum efficiency at one particular wind speed. At wind speeds above and below the rated wind speed, the energy capture does not reach the maximum value. Fixed-speed WECS are mechanically simple, reliable, stable, robust and well-proven. They have low cost maintenance and electrical parts. Conversely, these suffer from the disadvantages of mechanical stress, limited power quality control, and poor wind energy conversion efficiency.

\subsubsection{Variable-speed WECS}

As the size of WECS is becoming larger and the penetration of wind power in power system is increasing, the inherent problems of fixed-speed WECS become more and more pronounced, especially in areas with relatively weak supply grid. To overcome these problems and to comply with the grid-code connection requirements, the trend in modern WECS technology is to apply variable-speed concepts. With the developments in power electronics converters, which are used to connect wind turbines to the grid, variable speed wind energy systems are becoming common. The main advantages of variable-speed WECS are increased power capture, improved system efficiency, improved power quality with less flicker, reduced mechanical stress, reduced fatigue, and reduced acoustic noise. Additionally, the presence of power converters in wind turbines also provides high potential control capabilities for both large modern wind turbines and wind farms to fulfill the high technical demands imposed by the grid operators. The main features of variable-speed WECS are controllable active and reactive power (frequency and voltage control), quick response under transient and dynamic power system situations, influence on network stability and improved power quality. Their disadvantages include losses in power electronic elements and increased cost.

Variable-speed WECS are designed to achieve maximum aerodynamic efficiency over a wide range of wind speeds. It is possible to continuously adapt (increase or decrease) the rotational speed of WECS according to the wind speed. As the wind turbine operates at variable 
rotational speed, the electrical frequency of the generator varies and must therefore be decoupled from the frequency of the grid. This is achieved by using a power electronic converter system, between induction or synchronous generator and the grid. The power converter decouples the network electrical frequency from the rotor mechanical frequency enabling variable speed operation of the wind turbine. Variable-speed operation can be achieved by using any suitable combination of generator (synchronous or asynchronous) and power electronics interface, as it will be explained in the following subsections.

There are three main configurations of variable-speed converters. They are the limited variable-speed, the variable-speed with partial-scale frequency converter, and the variable-speed with full-scale frequency converter. These configurations can use any of the power-control mechanisms, namely stall, pitch or active stall control. As mentioned earlier, the pitch control mechanism is the most widely used.

\section{Limited variable-speed (the Type 2 WECS)}

This concept uses a wound rotor induction generator (WRIG), which is directly connected to the grid. A capacitor bank is used for reactive power compensation and a softstarter is employed for smoother grid connection. A unique feature of this concept is that it has a variable rotor resistance, which can be changed to control the slip. This way power output in the system is controlled, typical speed range being $0-10 \%$ above synchronous speed.

\section{Variable-speed with partial scale frequency converter (the DFIG or Type 3 WECS)}

This configuration, known as Doubly-Fed Induction Generator (DFIG), corresponds to the limited variable speed WECS with WRIG and a partial scale frequency converter (usually rated at approximately $30 \%$ of nominal generator power) on the rotor circuit. It uses a WRIG with slip rings to take current into or out of the rotor winding and variable speed operation is obtained by injecting a controllable voltage into the rotor at slip frequency. The rotor winding is fed through a variable frequency power converter, typically based on two AC/DC IGBT-based voltage source converters (VSCs) linked by a DC bus. A DFIG system delivers power to the grid through the stator whereas the rotor can either inject or absorb power, depending on the rotational speed of the generator. If the generator operates above synchronous speed, power will 
be delivered from the rotor through the converter to the network, and if the generator operates below synchronous speed, the rotor will absorb power from the network through the converters. The partial-scale frequency converter compensates for reactive power and provides a smoother grid connection. It has a relatively wide range of dynamic speed control, typically $\pm 30 \%$ around the synchronous speed. Its main drawbacks are the use of slip rings and high short-circuit currents in the case of grid faults (as compared to the Type $4 \mathrm{WG}$ - presented in the next subsection). Thus in this system, it is possible to control both active and reactive power, providing high grid performance. In addition, the power electronics converter enables the wind turbine to act as a more dynamic power source to the grid.

\section{Variable-speed with full-scale frequency converter (the Type 4 WECS)}

This configuration corresponds to the full variable speed wind turbine, with the generator connected to the grid through a full-scale frequency converter. The frequency converter compensates for reactive power compensation and provides a smoother grid connection. The generator is decoupled from the grid by a DC link. The power converter enables the system to control active and reactive power very fast. The generator can be electrically excited (WRIG or WRSG) or by a permanent magnet (PMSG). The gearbox may not be required in some configurations using a direct driven multipole generator. Enercon, Made and Lagerway are wellknown manufacturers of this topology. The synchronous generators and full-scale converters configuration is also referred to as Type 4 generators.

While DFIGs have gained popularity in recent years, Type 4 generators have been gradually capturing the market [8]. As compared to the DFIGs, Type 4 WECSs have a wider range for the controlled speed, are more efficient, less complicated, and easier to construct from an electrical engineering perspective [8]-[12]. In addition, the Type 4 WECS can be made directdriven system without using a gear box, resulting in reduced noise, installation and maintenance costs. SG can also be connected to diode rectifier or VSC. A major cost benefit is in using a diode bridge rectifier [7]. The synchronous generators can be electrically excited or excited by permanent magnets. The Permanent Magnet Synchronous Generators (PMSG) do not require external excitation current, meaning less losses, improved efficiency and more compact size [7], [13]. Further detailing of this topology is presented in the next section. 


\subsection{Synchronous Generator and Full-Scale Converter WECS}

The topology of the Type 4 WECS is shown in Fig. 2.2.

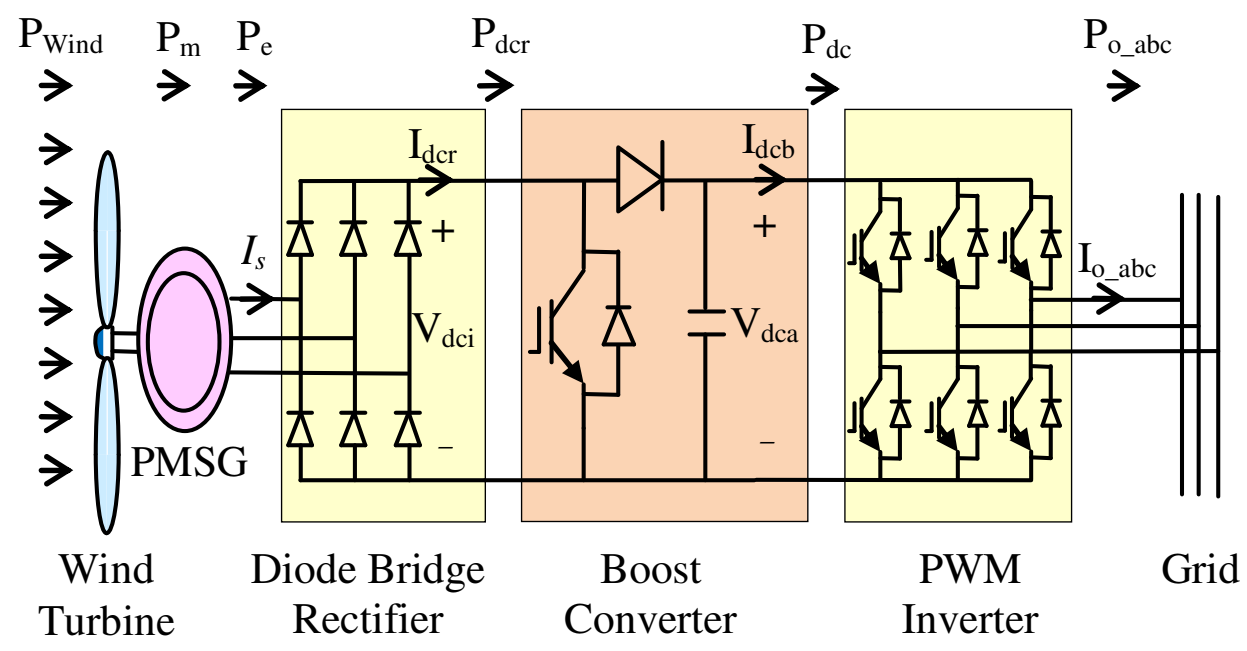

Figure 2.2: Synchronous generator and full-scale converter WECS

\subsubsection{Structure}

As shown in Figure 2.2, the Type 4 WECS is composed of a synchronous generator, a diode-bridge rectifier, a boost converter, and a Pulse-Width Modulation (PWM) Voltage Source Inverter (VSI).

\section{Generator}

The generator can be magnetised electrically or by permanent magnets. Two types of synchronous generators have often been used in the wind turbine industry: (1) the wound rotor synchronous generator (WRSG) and (2) the permanent magnet synchronous generator (PMSG). The wind turbine manufacturers Enercon, Lagerwey and Made apply the WRSG concept. Examples of wind turbine manufacturers that use the configuration with PMSGs are Lagerwey, WinWind and Multibrid. The synchronous generator with a suitable number of poles can be used for direct-drive applications without any gearbox. PMSGs do not require external excitation current, meaning less losses, improved efficiency and more compact size [7]-[13]. This is the topology studied in this thesis. 


\section{Converters}

The topology used in this thesis applies an uncontrolled diode-bridge rectifier as the generator-side converter. A DC booster is used to stabilize the DC link voltage whereas the network-side inverter (PWM VSI) controls the operation of the generator. The PWM VSI can be controlled using load-angle techniques or current controllers developed in a voltage-oriented dq reference frame. Another existing topology applies a PMSG and a power converter system consisting of two back-to-back voltage source converters.

Full-scale power converters ensure optimal wind energy conversion efficiency throughout their operating range and enable the WECS to meet various grid codes. Power converters are used to transfer power from the generator to the grid. The generator power is fed via the stator windings into the suitable power converters, which convert a three-phase AC voltage with variable frequency and magnitude into DC, and then convert the DC voltage into $\mathrm{AC}$ with fixed frequency and magnitude for grid connection. However, the grid-side converter, whose electric frequency and voltage are fixed to match those of the grid, can be set to control the injection of reactive power and imposed voltage on the grid. The specific characteristics and dynamics of the electrical generators are effectively isolated from the power network. Hence the output of the generator system may vary as the wind speed changes, while the network frequency remains unchanged, permitting variable speed operation. The power converter acts as an energy buffer for the power fluctuations caused by the wind and for transients coming from the grid side. Power converter can be arranged in various ways. While the generator-side converter (GSC) can be a diode-based rectifier or a PWM voltage source converter, the network-side converter (NSC) is typically a PWM source converter.

A DC inductor is used to smooth the ripple of the DC link. The small grid filter is used to eliminate the high order harmonics. These are not shown in figure.

\subsubsection{Operation}

The working principle of this generator is as follows (refer to Figure 2.2). The wind turbine axis is directly coupled to the generator rotor. Since the wind power fluctuates with the 
wind velocity, the PMSG output voltage and frequency vary continuously. The varying AC voltage is rectified into DC by the diode bridge rectifier $\left(\mathrm{V}_{\mathrm{dcr}}\right)$. The rectified DC voltage $\left(\mathrm{V}_{\mathrm{dcr}}\right)$ is boosted by the DC/DC boost converter by controlling its duty ratio to obtain a regulated voltage $\left(\mathrm{V}_{\mathrm{dca}}\right)$ across the capacitor. This $\mathrm{DC}$ voltage is inverted to obtain the desired AC voltage and frequency by using the PWM VSI. The WECS can be operated under power factor control mode to exchange only active power with the grid. 


\section{Chapter 3}

\section{Proposed Model of the Type 4 PMSG WECS}

The complete structure of a Type 4 PMSG WECS is modeled and validated in this chapter. Section 3.1 presents the modeling technique and section 3.2 presents the validation of the model.

\subsection{Model}

The complete model of the three-phase Type 4 WECS incorporates six sub-models: (1) a Wind Turbine, (2) a Permanent Magnet Synchronous Generator, (3) a three-phase diode-bridge rectifier, (4) a Boost Converter, (5) a Voltage Source Inverter, and (6) the control mode action.

Only the models at fundamental frequency are used in steady-state analysis of power systems. These models represent AC fundamental frequency and DC average values of voltages and currents [13]. The approach to develop models and equivalent circuit includes the balance of power and inclusion of converter losses [30]-[31]. In converters, the conduction losses depend on the on-state voltage, on-state resistance and current through it [32]. With the constant DC voltage, the converter losses can be represented by a constant value [13]. This is done by the drop across an equivalent series resistor which also includes the resistance of inductors [31]. Hence the equivalent circuit with a voltage source in series with impedance can be used for inclusion in the power flow [34]. The equivalent circuit of the complete model is shown in Figure 3.1.

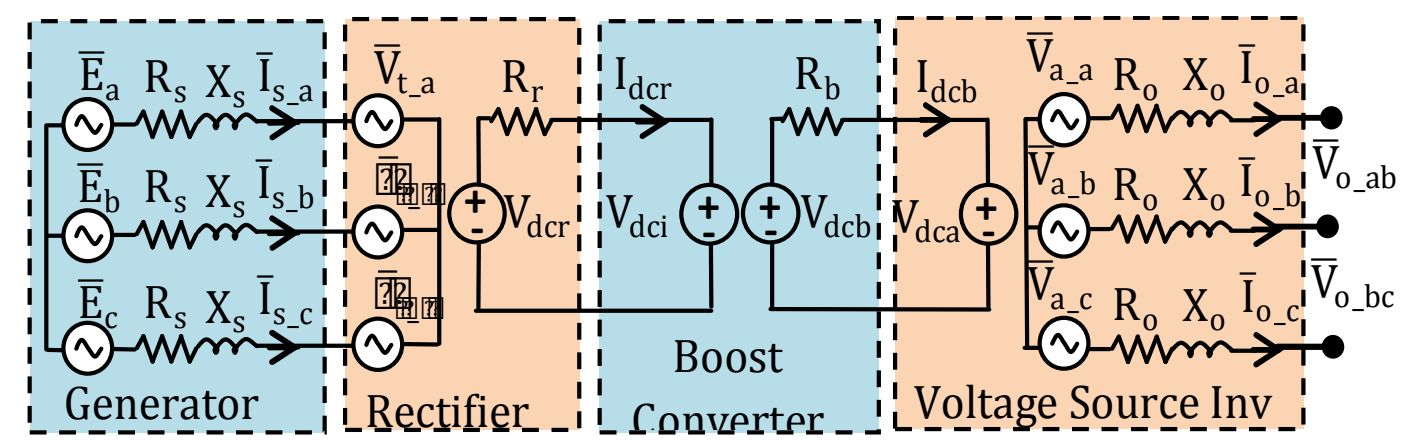

Figure 3.1: Proposed equivalent model for the Type 4 WECS 
The six following sub-sections describe the models of each of the five components, and the seventh sub-section presents the development of the proposed algorithm for obtaining the full model of the Type 4 PMSG WECS.

\subsubsection{Wind Turbine Model}

The wind turbine extracts a portion of wind power $\left(\mathrm{P}_{\text {wind }}\right)$ from the swept area of the rotor disc and converts it into mechanical power $\left(P_{m}\right)$ as determined below

$$
P_{m}=1 / 2 \cdot \rho \cdot A \cdot \omega_{\text {wind }}^{3} \cdot C_{p}
$$

where $\rho$ is the air density (approximately $\left.1.225 \mathrm{~kg} / \mathrm{m}^{3}\right), \mathrm{A}$ is the swept area of the rotor $\left(\mathrm{m}^{2}\right)$, and $\omega_{\text {wind }}$ is the free wind speed $(\mathrm{m} / \mathrm{s})$. The power coefficient $\left(\mathrm{C}_{\mathrm{P}}<0.593\right)$ can be maximized for a given wind speed by optimally adjusting the values of tip speed ratio and the blade pitch angle using data supplied by the manufacturer. In this thesis, through the optimal choice of $\mathrm{C}_{\mathrm{P}}$ for a given wind speed, $P_{m}$ and $\omega_{m}$ (rotor mechanical speed) are assumed to be known and are used as inputs to the synchronous generator.

\subsubsection{Synchronous Generator Model}

The induced EMFs (electromotive force) in the PMSG are considered sinusoidal [28] and the saturation of magnetic core and the effect of saliency of the rotor are neglected [16]. In the Type 4 PMSG WECS, the generator rotor shaft is directly coupled to the wind turbine such that they have a mechanical speed of $\omega_{\mathrm{m}}$.

The electrical speed $\left(\omega_{\mathrm{e}}\right)$, rotor mechanical speed $\left(\omega_{\mathrm{m}}\right)$, and the number of pair of poles $(\mathrm{p})$ are related as $\omega_{e}=p . \omega_{m}$. The PMSG is assumed balanced and its induced voltage in phase ph can be expressed as

$$
E_{p h}=4.44 \cdot \phi \cdot N \cdot \frac{\omega_{e}}{2 \pi}
$$


where $\square$ is magnetic flux which is a constant in a PMSG and N is the number of coil turns. This value is known a priori in this work.

Therefore, the generator terminal voltage in phase ph is obtained as

$$
V_{t_{-} p h} \angle \varphi_{t_{-} p h}=E_{p h} \angle \varphi_{s_{-} p h}-I_{s_{-} p h} \angle \theta_{s_{-} p h} \cdot\left(R_{s}+j X_{s}\right)
$$

where $\mathrm{R}_{\mathrm{s}}$ is the winding resistance and $\mathrm{X}_{\mathrm{s}}$ is the synchronous reactance. Also, $\varphi_{s_{-} p h}, \varphi_{t_{-} p h}$ and $\theta_{s_{-} p h}$ are the phase angles of $\bar{E}_{p h}, \bar{V}_{t_{-} p h}$ and phase current $\bar{I}_{S_{-} p h}$, respectively, for the phase ph. This equation defines the steady-state characteristic of the generator and can be represented by the corresponding equivalent circuit contained in Figure 3.1.

The generator's input mechanical power can be calculated as

$$
P_{m}=3 E_{p h} \cdot I_{s_{-} p h} \cdot \operatorname{Cos}\left(\varphi_{s_{p h}}-\theta_{s_{p h}}\right)
$$

\subsubsection{Three Phase Diode Bridge Rectifier Model}

Due to variations in wind speed, the generator output is of variable voltage and frequency. In order to achieve controllable speed in the WECS application, the first step consists of a three-phase diode-bridge rectifier being used to rectify the AC voltage into DC voltage. This device is of simple design and low cost. Thus, as the commutation effect is neglected, the generator output power factor is considered as unity. The rectifier output DC voltage is given by

$$
V_{d c r}=3 / \pi \cdot \sqrt{6} \cdot V_{t \_p h}
$$

The rectifier output DC current can be obtained as [35]

$$
I_{d c r}=\pi / \sqrt{6} \cdot I_{S_{-}} p h
$$


Finally, the terminal voltage of rectifier is given by

$$
V_{d c i}=V_{d c r}-R_{r} \cdot I_{d c r}
$$

where $R_{r}$ represents losses of the rectifier. The equivalent circuit used to represent the diodebridge rectifier is shown in Figure 3.1, which presents all major components of the Type 4 PMSG WECS. With the losses being represented in the series resistance $R_{r}$, the rectification process is power invariant and therefore:

$$
3 \cdot V_{t_{-} p h} \cdot I_{s_{-} p h} \cdot \operatorname{Cos}\left(\varphi_{t_{-} p h}-\theta_{s_{-} p h}\right)=V_{d c r} \cdot I_{d c r}
$$

\subsubsection{Boost Converter Model}

The DC voltage across the boost converter is controlled to be approximately constant and smooth by varying the duty cycle $\mathrm{D}$ in response to the variations in the input DC voltage. Thus it stabilizes the voltage at the DC terminal of the inverter [35]. The controlled DC voltage across of the boost converter is given by

$$
V_{d c b}=\frac{1}{(1-D)} V_{d c i}
$$

while the DC current output from the boost converter is

$$
I_{d c b}=(1-D) \cdot I_{d c r}
$$

Accounting for the Boost Converter losses in the series resistance $R_{b}$, the DC voltage output of the boost converter is calculated as

$$
V_{d c a}=V_{d c b}-R_{b} \cdot I_{d c b}
$$

Figure 3.1 shows the equivalent circuit used for the boost converter. 


\subsubsection{Voltage Source Inverter}

The connection of the WECS to the grid is done through a self commutated PWM VSI. A filter is typically used to limit harmonics [35]. The line-to-neural voltage at the VSI terminal is therefore

$$
V_{a \_p h}=\frac{\sqrt{3}}{2 \sqrt{2}} \cdot m_{a} \cdot V_{d c a}
$$

where $m_{a}$ is the modulation index that is bound as $0 \leq m_{a} \leq 1$.

The three-phase VSI output voltage is given by

$$
V_{o_{-} p h} \angle \varphi_{o_{-} p h}=V_{a_{\_} p h} \angle \varphi_{a_{\_} p h}-I_{o_{-} p h} \angle \theta_{o_{-} p h} .\left(R_{o}+j . X_{o}\right)
$$

The value of $R_{o}$ is chosen as to include all losses associated in the in the VSI. With $R_{o}$ representing all losses, the conversion process is power invariant and hence,

$$
3 V_{a_{\_} p h} \cdot I_{o_{-} p h} \cdot \operatorname{Cos}\left(\varphi_{a \_p h}-\theta_{o_{-} p h}\right)=V_{d c a} I_{d c b}
$$

The power output from the VSI can be written as

$$
P_{o_{-} p h}+j \cdot Q_{o_{-} p h}=V_{o_{-} p h} \angle \varphi_{o_{-} p h} \cdot\left(I_{o_{-} p h} \angle \theta_{o_{-} p h}\right)^{*}
$$

The equivalent circuit used for the PWM VSI is shown in Figure 3.1.

\subsubsection{Control Mode Action}

The Type 4 WECS is modeled to operate under the power factor control mode such that the output maintains a unity power factor. To represent the action of this control mode, at the bus where the WECS is connected (Point of Common Coupling - PCC), the reactive power balance equation is therefore given by 


$$
\sum_{p h=a, b, c} Q_{o_{-} p h}=0 .
$$

\subsubsection{Proposed Complete Type 4 PMSG WECS Model Algorithm}

Subsections 3.1.1-3.1.6 were used to develop the models of the important elements of the Type 4 PMSG WECS. The complete model was shown in Figure 3.1. The equations presented in the previous sections used to represent the behaviour of the Type 4 generator are:

- Wind turbine: (1);

- Synchronous Generator Model: (2)-(4);

- Diode Bridge Rectifier: (5) - (8);

- Boost Converter: (9)-(11);

- Voltage Source Inverter: (12)-(15);

- Controller: (16)

\subsection{Validation}

In this section, the developed model is validated by using time-domain simulation via the Matlab-Simulink package. The Simulink diagram is shown in Figure 3.2. By using this model at any given wind speed and bus bar voltage, the complete state of the Type 4 PMSG WECS can be computed. During the validation process, the WECS is operated in the power factor control mode. 


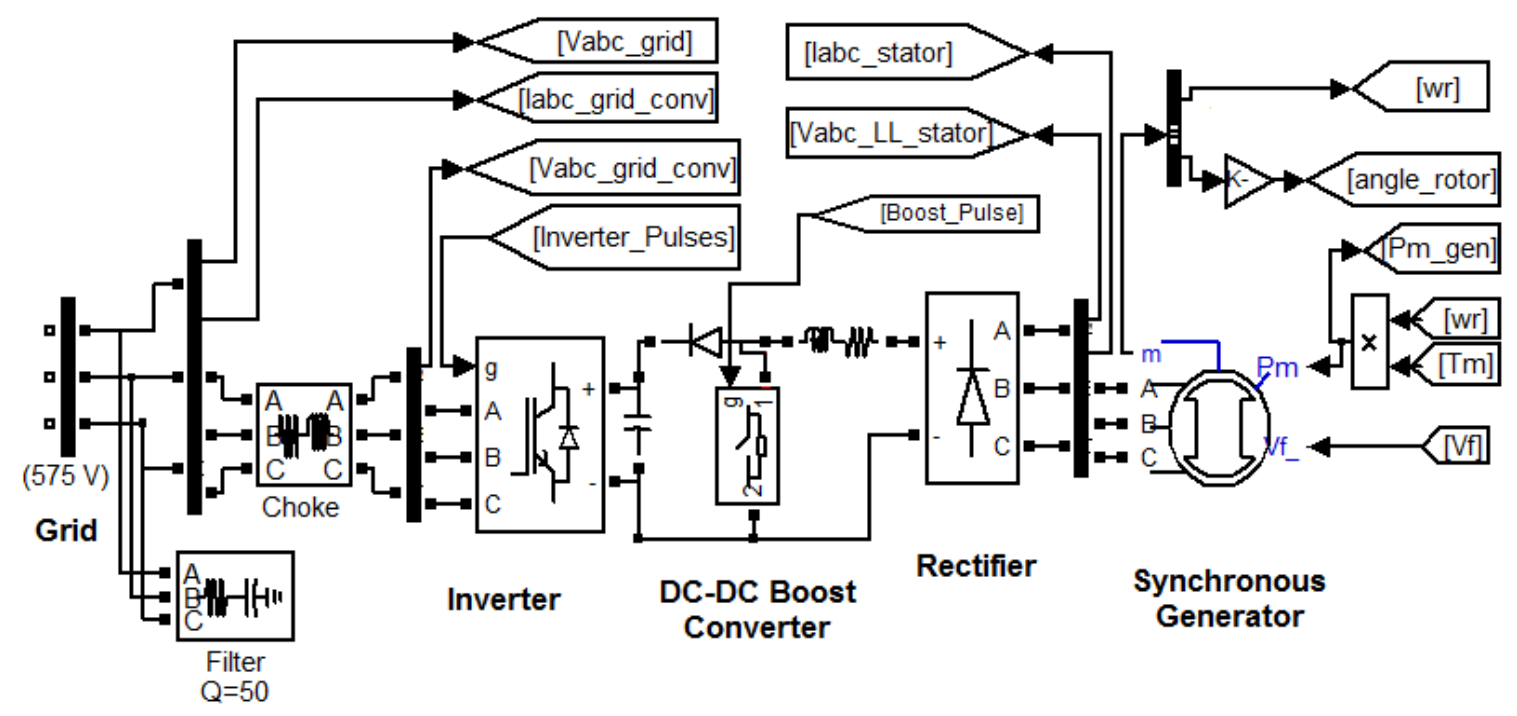

Figure 3.2: Type 4 WECS model in Matlab-Simulink

The results are tabulated in Table 3.1. The PMSG, Rectifier, Boost Converter and PMW VSI data sets were used according to [37], and are presented in Appendix A. On solving the same data set as that used by MATLAB-Simulink, virtually identical results were obtained. Further, using hand calculations, the same results as those of the proposed model were obtained. These results in Table 3.1 validate the proposed model.

Table 3.1: Results from both models for the Type 4 WECS

\begin{tabular}{|l|l|l|}
\hline Parameter & Matlab-Simulink Model & Proposed Model \\
\hline $\mathrm{P}_{\mathrm{m}}(\mathrm{MW})$ & 2.07711 & 2.07711 \\
\hline $\mathrm{V}_{\mathrm{t} \_ \text {ph }}($ Volt $)$ & $412.805 \angle 0$ & $412.805 \angle 0$ \\
\hline $\mathrm{P}_{\mathrm{e}}(\mathrm{MW})$ & 2.07468 & 2.07474 \\
\hline $\mathrm{V}_{\mathrm{dcr}}($ Volt $)$ & 910.2 & 910.2 \\
\hline $\mathrm{P}_{\mathrm{dcr}}(\mathrm{MW})$ & 2.04430 & 2.04428 \\
\hline $\mathrm{V}_{\mathrm{dcb}}(\mathrm{Volt})$ & 1100 & 1100 \\
\hline $\mathrm{P}_{\mathrm{dcb}}(\mathrm{MW})$ & 2.02686 & 2.02686 \\
\hline $\mathrm{V}_{\mathrm{o} \_ \text {ph }}($ Volt $)$ & $339.533 \angle 0$ & $339.533 \angle 0$ \\
\hline $\mathrm{P}_{\mathrm{o} \_ \text {abc }}(\mathrm{MW})$ & 2.00589 & 2.00592 \\
\hline
\end{tabular}

Note: The proposed model was also verified analytically. 
The Simulink model has been used for validation purposes only and it would have serious limitations should it be used for load flow analysis because of computational time. For a simple 2-bus system, the Simulink model takes 10-20 times longer to compute than the proposed model and for larger system this time difference will escalate. 


\section{Chapter 4}

\section{New Load Flow Approach with the Proposed Type 4 WECS Model}

There are many efficient and reliable load flow solution techniques, which have been developed and widely used for power system operation, control and planning in the transmission level. Most of the WECS units are being connected in distribution networks. Generally, distribution systems are radial and have a high $\mathrm{R} / \mathrm{X}$ ratio. Therefore distribution systems power flow computation is different and the conventional Load Flow methods may fail to converge to a solution. Moreover, most of the distribution systems are unbalanced because of single-phase, two-phase and three-phase loads. Traditional load flow programs are designed to model only balanced three-phase power systems. Therefore, the traditional power flow methods may not be able to solve power flow problems of distribution systems in the presence of DGs. Recently, various methods have been developed to carry out the analysis of balanced and unbalanced radial distribution systems. A first category of methods is based on the modification of existing methods such as the Newton-Raphson and Gauss-Seidel and the second category is based on forward and/or backward sweep processes using Kirchoff's Laws.

Forward/backward sweep-based algorithms are more popular because of their low memory requirements, high computational efficiency and reliable convergence characteristic. These methods take advantage of the radial nature of distribution networks where there is a unique path from any given bus to the source.

In this chapter a new approach of load flow to which the proposed Type 4 PMSG WECS model is integrated and presented. A comparison with the traditional fixed PQ model is also presented.

\subsection{Load Flow Method Description}

There are many variants of Forward/backward sweep-based methods but the basic algorithm is the same. The general algorithm consists of two basic steps, backward sweep and 
forward sweep, which are repeated until convergence is achieved. The backward sweep is primarily a branch current or power flow summation with possible voltage updates, from the receiving end to the sending end of the feeder and/or laterals. The forward sweep is primarily a node voltage drop calculation with possible current or power flow updates. The load flow technique based on the ladder network theory is used in this study [38].

A detailed explanation on the ladder iterative technique is presented in this section. The flowchart presented in figure 4.1 presents the steps of the ladder-iterative technique power flow algorithm. 


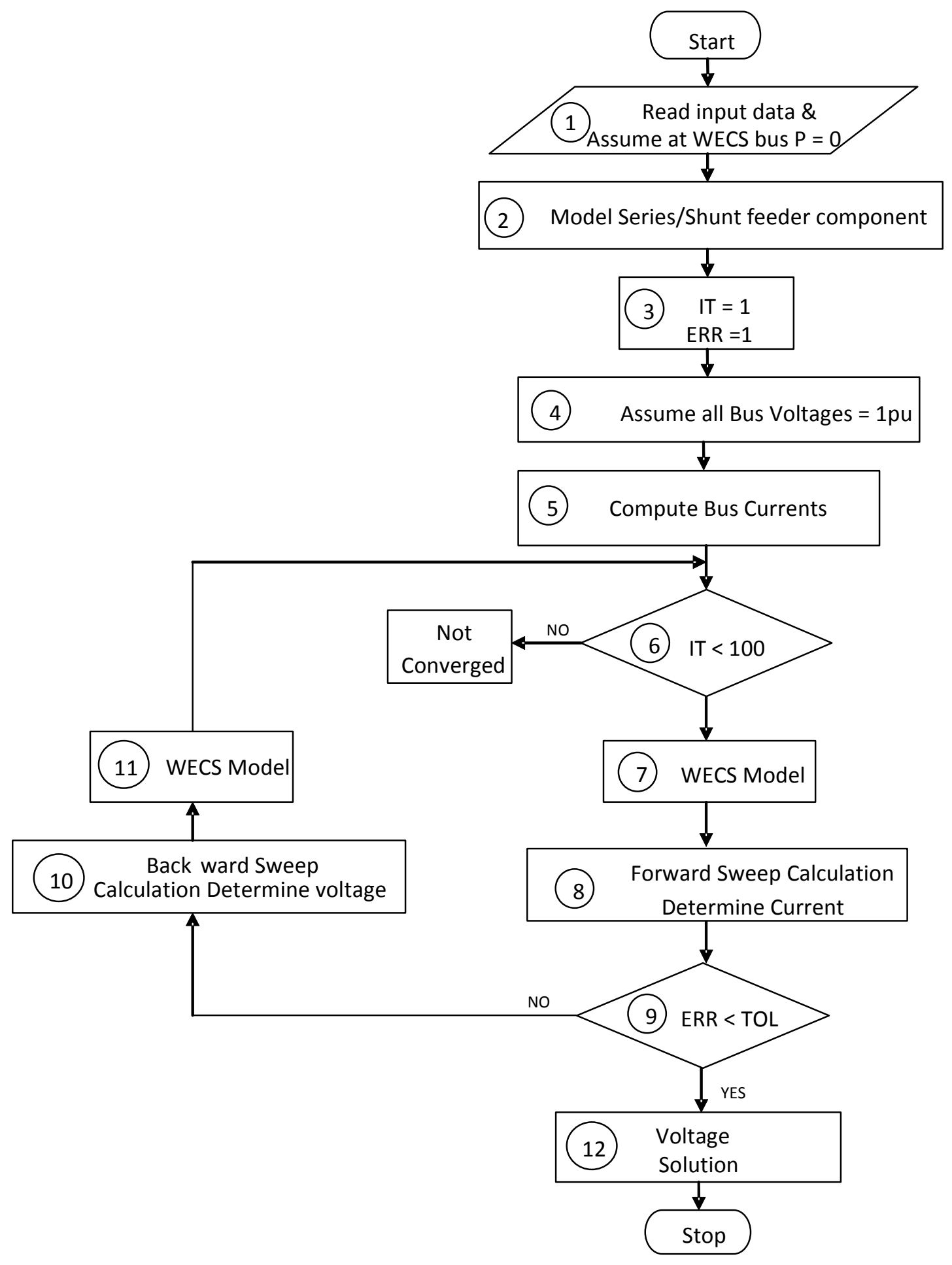

Figure 4.1: Flowchart of Load Flow using conventional Ladder Iterative Technique 
Each step of this algorithm is presented in detail as follows.

\section{Step 1: Read input data}

The Matlab code including the algorithm to read the data is given in Appendix D. Initially at WECS bus, power generation/consumption is considered as zero, i.e., $\mathrm{P}_{\mathrm{abc}}=\mathrm{Q}_{\mathrm{abc}}=0$.

\section{Step 2: Modeling of Series Feeder Components}

Different Series Feeder Components (SFC), such as lines, transformers, and etc, are modeled to compute the generalized matrices a, b, c, d, A and B, which will be used in Step 8. This modeling procedure is explained in Appendix C.

Step 3: Initialisation: assume IT $=1$ and $E R R=1$

Step 4: Assume $\overline{\mathbf{V}}_{\text {bus }}=1$ pu at all buses

Voltage at all buses is assumed to be the same as the source voltage, i.e., $=1$ p.u.

\section{Step 5: Compute the bus currents}

Bus load currents and thus bus currents at all buses, including the WECS bus, are computed using the appropriate relations, depending on the type of load, as specified in Appendix B.

\section{Step 6: While IT $<100$}

The maximum number of iterations is specified (refer to algorithm in Appendix D).

\section{Step 7: Integrate the WECS model}

The Type 4 WECS model, as given in Appendix E, is integrated and values of system loads ( $\mathrm{P}$ and Q) are updated. 


\section{Step 8: Forward Sweep Calculation}

The current is determined during the Forward Sweep, starting from the last node and sweeping every node until the first node (or source) is reached. After integrating the WECS model, bus load currents and thus bus currents are updated, similarly to what was done in step 5. The line current flowing from the last node to the first node is found. The voltage at the next bus and line current in next section are updated by using this line current, the voltage at the previous node and the a, b, c, d parameters obtained in Step 2.

The bus load currents and the bus currents are updated using updated bus voltages.

\section{Step 9: Compute ERR and Check ERR<TOL}

The error is computed by comparing the voltage found at the first bus in step 8 with the specified voltage (i.e., 1 p.u.) at the first bus.

If this Error is more than the tolerance specified in the data file, then proceed with the Backward sweep (Step 10); otherwise go to Step 12.

The processes of Forward sweep and Backward sweep continue until the error is smaller than the specified tolerance value.

\section{Step 10: Backward Sweep Calculation}

During the Backward sweep, the voltage is determined, starting from the source node to the end node.

The voltage at a node is determined using the specified voltage from the previous node, the forward sweep bus current (Step 8) flowing between nodes, and the A \& B parameters obtained from the models of series components (Step 2).

In this way, the updated new voltages at all end nodes are computed. 


\section{Step 11: IT $=$ IT +1}

This completes the first iteration and the next iteration will start at Step 6. Now the forward sweep calculation will start by using the new updated end voltages determined in the backward sweep of the previous iteration.

\section{Step 12: Solution:}

The forward sweep and backward sweep calculations are continued until the calculated voltage at the source or first node is smaller than the specified tolerance value, i.e., until ERR $<$ TOL. At this point the voltages at all nodes and current flowing in all components / segments are known.

\subsection{Test System Description}

In this section, the unbalanced IEEE 37-bus test system (presented in [39]) is used to test the proposed Type 4 WECS model. The proposed WG model was installed on bus \# 775, as shown in Figure 4.2.

Further changes were made into the original IEEE 37-bus system as follows:

1. The $2 \mathrm{MW}$ rated Type $4 \mathrm{WG}$ was connected to bus $\# 775$.

2. According to the $W G$ rating, the rating of the transformer XFM-1 was changed from 500 $\mathrm{kVA}$ to $2 \mathrm{MVA}$, and its low voltage side rating was changed from $480 \mathrm{~V}$ to $575 \mathrm{~V}$.

3. To clearly understand the effect of the WG model on the system, a 1.0 MW load was added to each of the phases of buses \# 730 and \# 731. These additional loads make voltage changes at the WG bus more pronounced. 


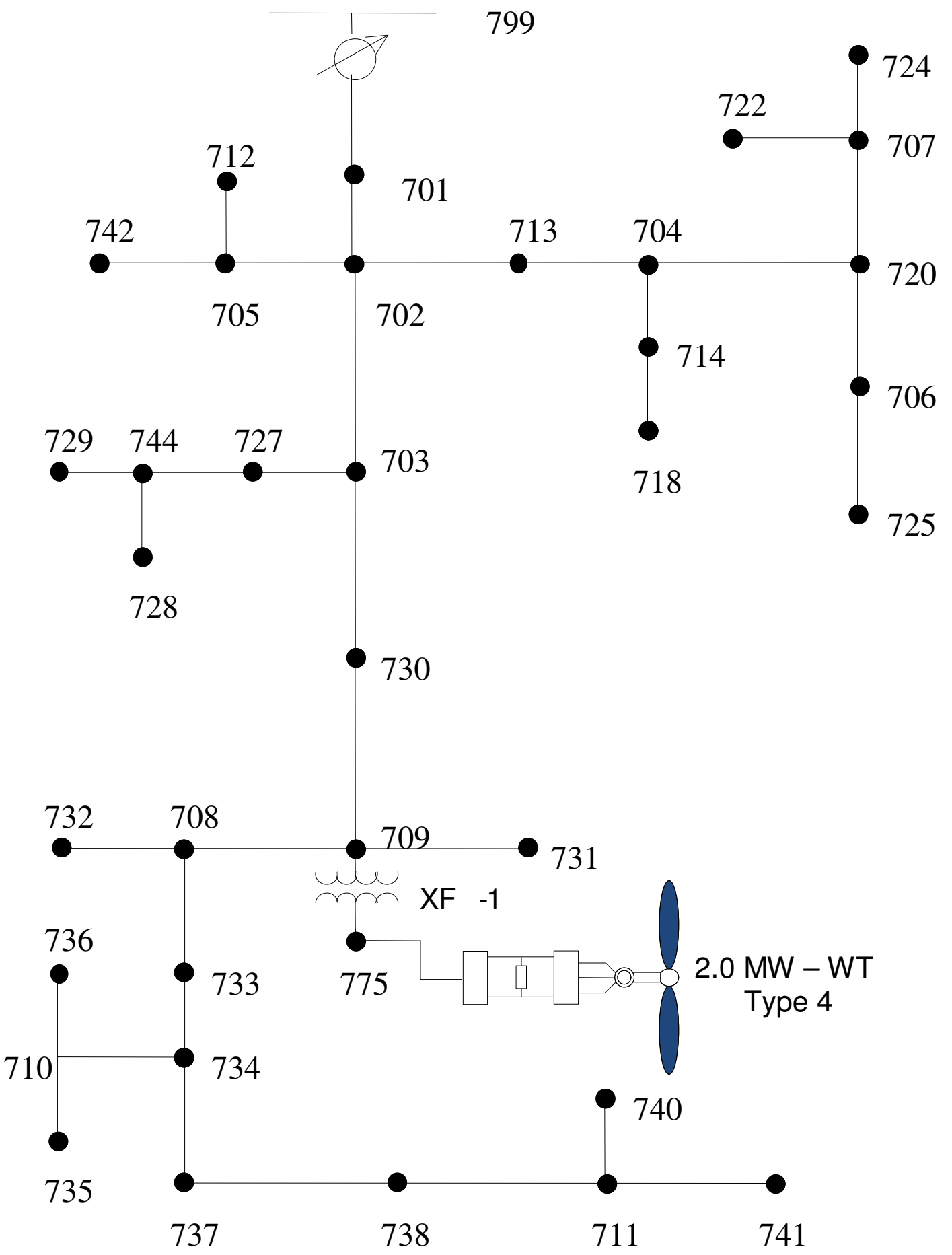

Figure Type 4.2: WECS connection to the IEEE 37-bus test system 


\subsection{WECS Model in Load Flow Analysis - Two Approaches}

The flowchart of ladder iterative technique is presented in Figure 4.3. The shaded box in Figure 4.3 is the step that defines the real and reactive power transacted by the Type 4 wind generator.

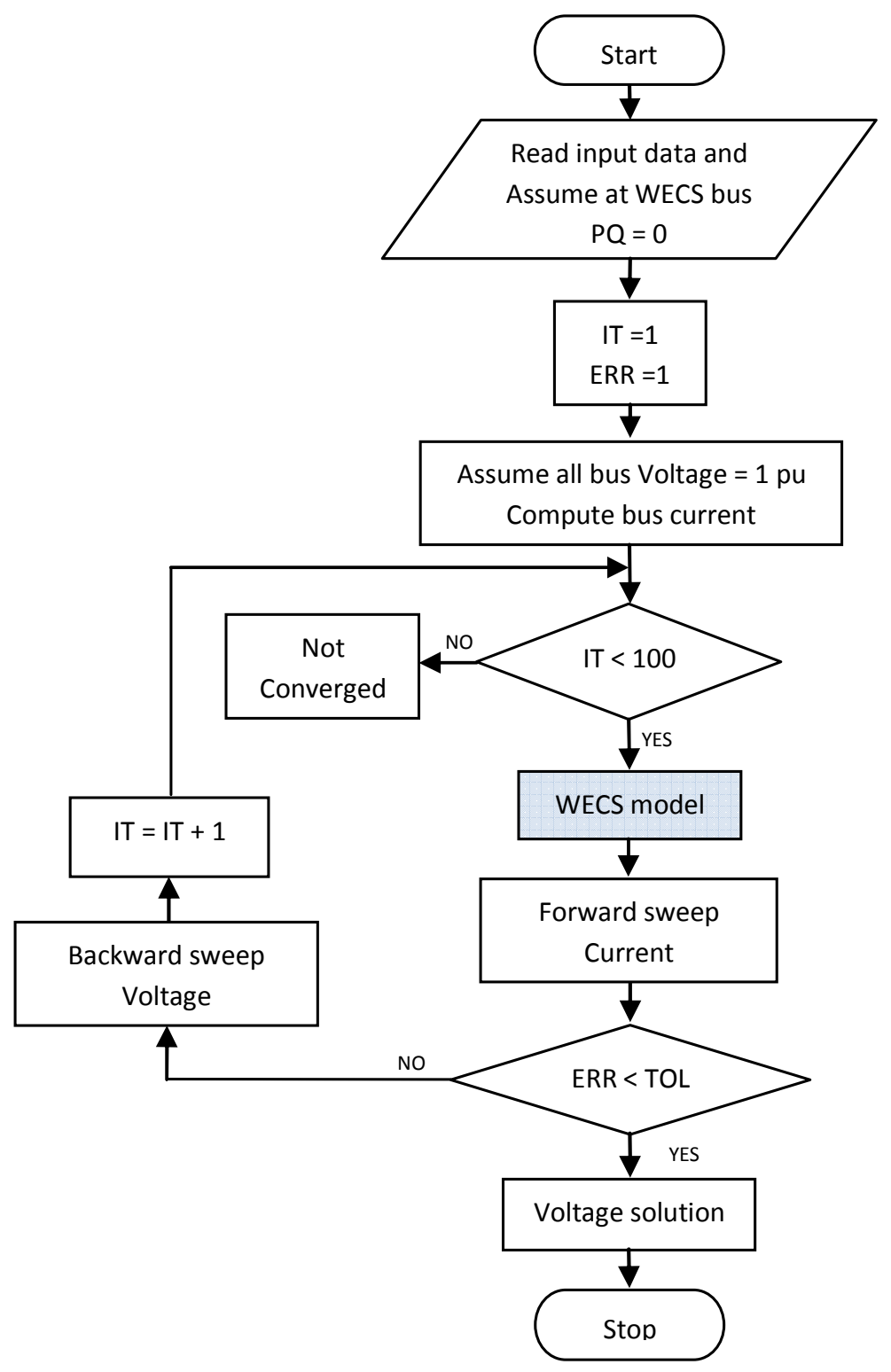

Figure 4.3: Flowchart of Load Flow with Ladder Iterative Technique

Depending on the Type 4 generator model being used, power flow analysis can be carried in two different approaches. In the first approach (LF-1), the voltage solution is determined by solving 
the power flow equations with the WECS represented as a fixed $P Q$ load, i.e., $P=P_{a}=P_{b}=P_{c}$, and $Q=Q_{a}=Q_{b}=Q_{c}$ are considered as input to the connection bus. This is the traditional approach that has been widely adopted by industry. In the proposed approach (LF-2), the voltage solution is determined by solving the power flow equations with the proposed WECS model as presented in section 3.1 .

\subsubsection{Conventional Load Flow Method with the Conventional Type 4 WECS Model (LF- 1)}

In this approach (LF-1), the Type 4 wind generator is represented as a fixed $P Q$ load. To represent the power factor control operating mode, the reactive power output of the Type 4 WECS was set to zero. For all iterations of the power flow algorithm (which was shown in Figure 4.3), it was assumed that the Type 4 WECS generates fixed active power equal to $\mathrm{P}_{\mathrm{abc}}=-$ $0.66832 \mathrm{MW}$ in each of the phases, respectively. The results of this traditional method are shown in Table 4.1 and Figure 4.4.

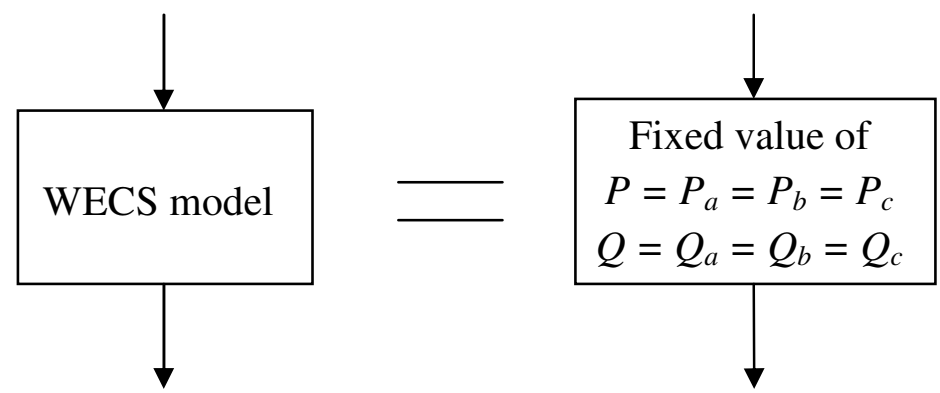

Figure 4.4: WECS modeled as a fixed $P Q$ load

\subsubsection{New Load Flow Method with the Proposed Type 4 WECS Model (LF-2)}

In this proposed power flow algorithm (LF-2), the Type 4 PSMG WECS developed in section 2.1 was incorporated into the ladder iterative technique. The diagram of the proposed algorithm for the generator model is shown in Figure 4.5. The set of nonlinear equations that characterize the WG model is solved using a standard nonlinear equation solver in each iteration 
of the power flow algorithm. It computes the WG bus voltage computed in the preceding iteration of the power flow algorithm.

In the first iteration of the ladder iterative technique, all bus voltages are assumed to be 1 p.u. Therefore, the initial value of the PMSG WECS is also equal to $\mathrm{P}_{\mathrm{a}}=\mathrm{P}_{\mathrm{b}}=\mathrm{P}_{\mathrm{c}}=-0.66832 \mathrm{MW}$ and reactive power is $0 \mathrm{MVAr}$ on each phase. The resulting $\mathrm{P}_{\mathrm{abc}}$ and $\mathrm{Q}_{\mathrm{abc}}$ act as a negative load bus model for the next power flow iteration. In the following iterations, due to the presence of unbalanced voltages, loads and system parameters, the PMSG WECS terminal voltage becomes unbalanced and the PMSG WECS model yields unbalanced real power output values. The same process will repeat until convergence. In each iterative step of the power flow algorithm, the PMSG WECS model gives the actual value of currents, voltages, powers and losses on each phase.

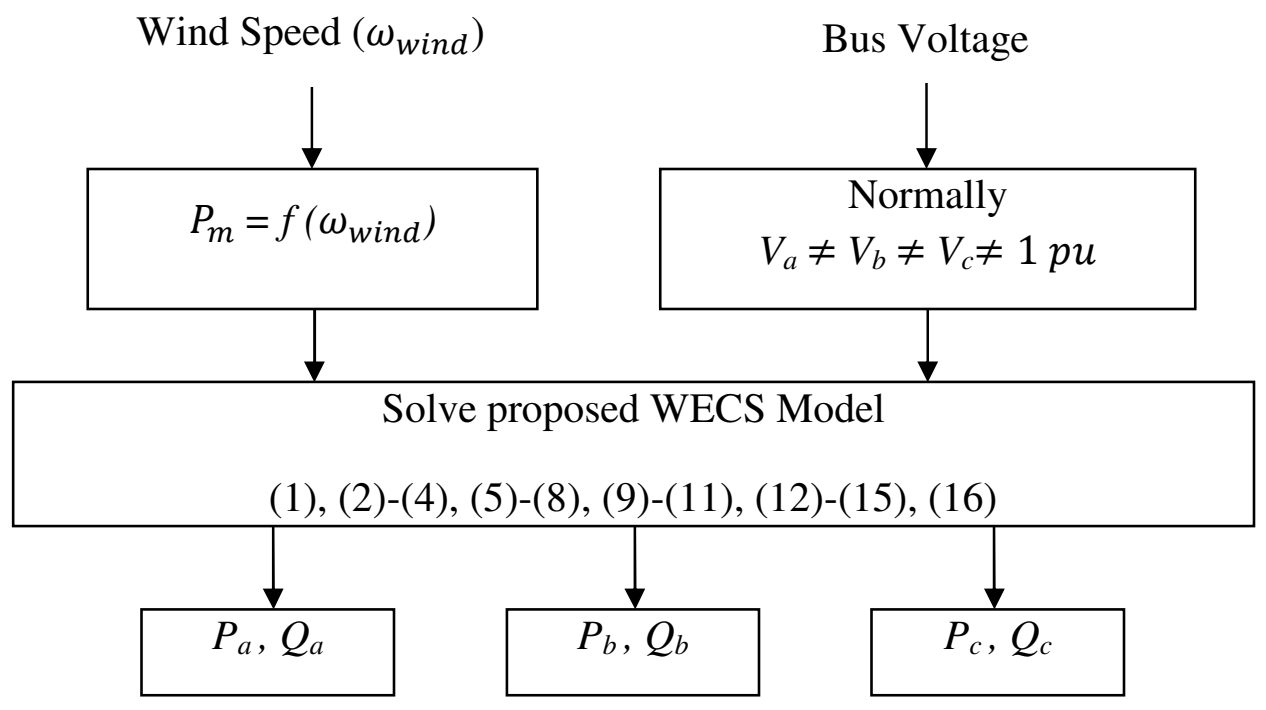

Figure 4.5: Proposed WECS model integrated in the Load Flow solution

\subsubsection{Results and Comparison of the Power Flow Methods}

The proposed Type 4 PMSG WECS model was integrated into the IEEE 37-bus unbalanced test system for power flow studies. The voltage solutions of both power flow approaches LF-1 (fixed PQ) and LF-2 (proposed WECS model) are presented in Table 4.1. 
Table 4.1: Comparison of results from Load Flow methods for the IEEE 37-bus test system

\begin{tabular}{|c|c|c|c|c|c|c|}
\hline \multirow[t]{2}{*}{$\begin{array}{c}\text { Bus } \\
\text { Name }\end{array}$} & \multicolumn{2}{|c|}{$\begin{array}{c}\text { Phase a-b } \\
V_{\text {ab }}(p u)\end{array}$} & \multicolumn{2}{|c|}{$\begin{array}{c}\text { Phase b-c } \\
\text { V bc }_{\text {bu) }}\end{array}$} & \multicolumn{2}{|c|}{$\begin{array}{c}\text { Phase c-a } \\
V_{\text {ca }}(\mathbf{p u})\end{array}$} \\
\hline & LF 1 & LF 2 & LF 1 & LF 2 & LF 1 & LF 2 \\
\hline 799 & 1.0000 & 1.0000 & 1.0000 & 1.0000 & 1.0000 & 1.0000 \\
\hline RG7 & 1.0437 & 1.0437 & 1.0250 & 1.0250 & 1.0345 & 1.0345 \\
\hline 701 & 1.0193 & 1.0192 & 1.0022 & 1.0022 & 1.0033 & 1.0034 \\
\hline 702 & 1.0029 & 1.0027 & 0.9883 & 0.9883 & 0.9846 & 0.9847 \\
\hline 703 & 0.9831 & 0.9827 & 0.9732 & 0.9734 & 0.9640 & 0.9641 \\
\hline 727 & 0.9819 & 0.9816 & 0.9726 & 0.9727 & 0.9630 & 0.9631 \\
\hline 744 & 0.9812 & 0.9809 & 0.9722 & 0.9723 & 0.9625 & 0.9627 \\
\hline 728 & 0.9808 & 0.9805 & 0.9718 & 0.9720 & 0.9621 & 0.9623 \\
\hline 729 & 0.9809 & 0.9805 & 0.9721 & 0.9723 & 0.9624 & 0.9626 \\
\hline 730 & 0.9627 & 0.9622 & 0.9564 & 0.9567 & 0.9440 & 0.9442 \\
\hline 709 & 0.9600 & 0.9595 & 0.9546 & 0.9548 & 0.9416 & 0.9418 \\
\hline 708 & 0.9575 & 0.9570 & 0.9535 & 0.9538 & 0.9393 & 0.9395 \\
\hline 732 & 0.9574 & 0.9570 & 0.9534 & 0.9536 & 0.9388 & 0.9390 \\
\hline 733 & 0.9551 & 0.9546 & 0.9525 & 0.9528 & 0.9373 & 0.9375 \\
\hline 734 & 0.9517 & 0.9512 & 0.9510 & 0.9513 & 0.9339 & 0.9341 \\
\hline 710 & 0.9512 & 0.9507 & 0.9500 & 0.9502 & 0.9323 & 0.9325 \\
\hline 735 & 0.9511 & 0.9506 & 0.9498 & 0.9501 & 0.9318 & 0.9320 \\
\hline 736 & 0.9506 & 0.9502 & 0.9484 & 0.9487 & 0.9320 & 0.9322 \\
\hline 737 & 0.9483 & 0.9478 & 0.9500 & 0.9503 & 0.9317 & 0.9319 \\
\hline 738 & 0.9471 & 0.9466 & 0.9496 & 0.9499 & 0.9306 & 0.9308 \\
\hline 711 & 0.9468 & 0.9463 & 0.9494 & 0.9497 & 0.9296 & 0.9298 \\
\hline 740 & 0.9467 & 0.9462 & 0.9493 & 0.9495 & 0.9291 & 0.9293 \\
\hline 741 & 0.9468 & 0.9463 & 0.9494 & 0.9496 & 0.9293 & 0.9295 \\
\hline 731 & 0.9479 & 0.9474 & 0.9429 & 0.9432 & 0.9299 & 0.9301 \\
\hline XF7 & 0.9600 & 0.9595 & 0.9546 & 0.9548 & 0.9416 & 0.9418 \\
\hline WECS & 0.9599 & 0.9593 & 0.9551 & 0.9554 & 0.9419 & 0.9421 \\
\hline
\end{tabular}




\begin{tabular}{|l|l|l|l|l|l|l|}
\hline 705 & 1.0023 & 1.0020 & 0.9869 & 0.9870 & 0.9833 & 0.9834 \\
\hline 712 & 1.0021 & 1.0019 & 0.9867 & 0.9868 & 0.9827 & 0.9828 \\
\hline 742 & 1.0019 & 1.0017 & 0.9861 & 0.9862 & 0.9831 & 0.9832 \\
\hline 713 & 1.0015 & 1.0013 & 0.9864 & 0.9865 & 0.9828 & 0.9829 \\
\hline 704 & 0.9998 & 0.9996 & 0.9838 & 0.9839 & 0.9810 & 0.9811 \\
\hline 714 & 0.9996 & 0.9994 & 0.9837 & 0.9838 & 0.9809 & 0.9810 \\
\hline 718 & 0.9983 & 0.9980 & 0.9835 & 0.9836 & 0.9805 & 0.9806 \\
\hline 720 & 0.9986 & 0.9984 & 0.9804 & 0.9805 & 0.9785 & 0.9786 \\
\hline 706 & 0.9985 & 0.9983 & 0.9800 & 0.9801 & 0.9784 & 0.9785 \\
\hline 725 & 0.9984 & 0.9982 & 0.9796 & 0.9797 & 0.9783 & 0.9784 \\
\hline 707 & 0.9968 & 0.9966 & 0.9753 & 0.9754 & 0.9770 & 0.9771 \\
\hline 722 & 0.9966 & 0.9964 & 0.9747 & 0.9748 & 0.9768 & 0.9769 \\
\hline 724 & 0.9965 & 0.9963 & 0.9743 & 0.9744 & 0.9768 & 0.9769 \\
\hline
\end{tabular}

LF-1: WG modeled as a Fixed PQ load LF-2: Proposed WG model

Figure 4.6 further quantifies the difference between the results from the two power flow methods. Figure 4.6 shows that the difference between the line to line voltage (phases a-b) solutions for both power flow methods is about 0.006 p.u. at the bus connecting the WECS and nearby buses.

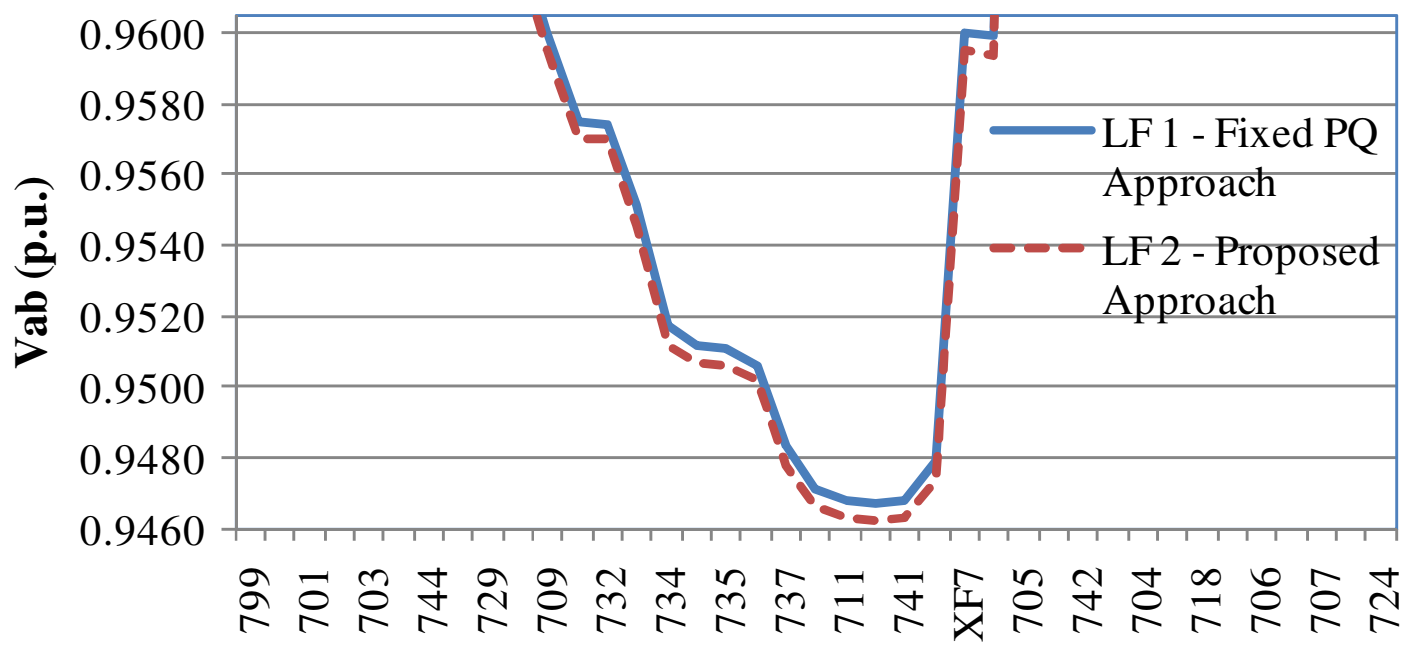

\section{Bus Number}

Figure 4.6: Comparison of line to line voltage a-b for both Load Flow approaches 
This comparison between the voltage solutions obtained by the two types of power flow methods (LF-1 and LF-2) highlights the impact of the proposed active Type 4 PMSG WECS model on each phase of the system. Significant differences in voltage and power on the generator bus for both power flow methods can also be noticed and are summarized in Table 4.2.

Table 4.2: Comparison of voltages and powers at the bus connecting the Type 4 WECS for both Load Flow methods

\begin{tabular}{|c|c|c|c|c|}
\hline \multirow{2}{*}{} & \multicolumn{2}{|c|}{ LL bus Voltage (p.u.) } & \multicolumn{2}{c|}{ WECS bus power (MW) } \\
\hline & $\begin{array}{c}\text { LF-1 } \\
\text { Fixed PQ }\end{array}$ & $\begin{array}{c}\text { LF-2 } \\
\text { Proposed }\end{array}$ & $\begin{array}{c}\text { LF-1 } \\
\text { Fixed PQ }\end{array}$ & $\begin{array}{c}\text { LF-2 } \\
\text { Proposed }\end{array}$ \\
\hline Phase-a & 0.9599 & 0.9593 & -0.668 & -0.655 \\
\hline Phase-b & 0.9551 & 0.9554 & -0.668 & -0.684 \\
\hline Phase-c & 0.9419 & 0.9421 & -0.668 & -0.664 \\
\hline
\end{tabular}

To further verify the correctness of the power flow results obtained using the proposed WG model, the following procedure was adopted.

1. The power output of the Type 4 WECS, as determined using the proposed model and presented in Table 4.2, was taken as fixed PQ load $\left(P_{a}=-0.655 \mathrm{MW}, P_{b}=-0.684 \mathrm{MW}, P_{c}=\right.$ - $0.664 \mathrm{MW}$, and $Q_{a}=Q_{b}=Q_{c}=0$ ). Using this WG input in the first iteration of the ladder iterative technique, the voltage solution was obtained. This voltage solution was identical to the results obtained using the proposed model $\left(V_{s a b}=0.9593\right.$ p.u., $V_{s b c}=0.9554$ p.u., $V_{s c a}=$ 0.9421 p.u.).

2. Using this Type 4 WECS model on MATLAB-Simulink, bus voltages were taken as $\left(V_{s a b}=\right.$ 0.9593 p.u., $V_{s b c}=0.9554$ p.u., $V_{s c a}=0.9421$ p.u. $)$. The same power output was obtained: $\left(P_{a}\right.$ $\left.=-0.655 \mathrm{MW}, P_{b}=-0.684 \mathrm{MW}, P_{c}=-0.664 \mathrm{MW}\right)$. These results confirmed the correctness of the proposed Type $4 \mathrm{WG}$ model and of the proposed power flow approach LF-2. 


\section{Chapter 5}

\section{Conclusions and Suggestions for Future research}

\subsection{Conclusions}

The Type 4 WECS (Synchronous Generator and Full-Scale Inverter) has gained popularity and is capturing the market of wind generators. Traditionally, the Type $4 \mathrm{WG}$ has been modeled as a fixed negative PQ load in power flow studies. This fixed PQ model of a Type 4 WG leads to inaccurate voltage solutions in power flow studies. With the widespread use of this technology of wind generator in distribution systems, their accurate modeling is imperative, and is the focus of this thesis. The main contributions of this research work can be summarized as follows:

1. This thesis has presented the development of an accurate three-phase model using a set of nonlinear equations. The proposed model accounts for the synchronous generator, the wind turbine, the three-phase diode bridge rectifier, the Boost converter, the PWM VSI, and the Control Mode Action.

2. The proposed model was validated by comparing its results with those obtained from MATLAB-Simulink and via analytical calculations. The proposed model takes much less computational time than the Simulink model. For larger system, this time difference is further increased.

3. The proposed model can be easily integrated into power flow algorithms. The integrated power flow algorithm was presented and discussed.

4. Power Flow analysis results of an unbalanced three-phase IEEE 37-bus test system were reported. The results obtained using the fixed PQ and the proposed models were compared. The proposed model was once again validated using the 37-bus test system and therefore shown to be accurate.

5. The proposed model creates an accurate three-phase representation of a Type $4 \mathrm{WG}$ that is suitable for power flow studies under unbalanced conditions. It is suitable for the ladder iterative technique (as shown in this thesis) and equally suitable for NewtonRaphson Technique as well. 


\subsection{Suggestions for Future Research}

The following are the suggestions for future research development.

- During this research work, the commutation effect in the synchronous-diode rectifier pair was neglected. Further switching losses of converters were also neglected. Therefore, it is possible to further modify the model by including these losses to obtain an even more accurate model.

- A more detailed load flow analysis could also include models of other types of WECS along with the Type 4 model. This would enable representing real distribution feeders populated with a mix of different types of WECS. 


\section{References}

1. O. Anaya-Lara, N. Jenkins, J. Ekanayake, P. Cartwright, and M. Hughes , "Wind Energy Generation: Modelling and Control ”, John Wiley \& Sons Ltd, 2009.

2. F. Iov, M. Ciobotaru, and F. Blaabjerg, "Power Electronics Control of Wind Energy in Distributed Power Systems."

3. Z. Chen, "Wind turbine power converters: a comparative study," Seventh International Conference on Power Electronics and Variable Speed Drives, 1998, pp. 471-476.

4. Global Wind Energy Council, available online at http://www.gwec.net/index.php?id=97

5. Canadian Wind Energy Association, available online at http://www.canwea.ca/media/index_e.php

6. T. Ackermann, "Wind Power in Power Systems", John Wiley \& Sons Ltd, 2005 pp. 6469.

7. J.A. Baroudi, V. Dinavahi, and A.M. Knight, "A review of power converter topologies for wind generators," Renewable Energy, vol. 32, 2007, pp. 2369-2385.

8. A.D. Hansen and L.H. Hansen, "Wind Turbine Concept Market Penetration over 10 Years (1995-2004),” Wind Energy, vol. 10, 2007, pp. 81-97.

9. H. Li and Z. Chen, "Overview of different wind generator systems and their comparisons," IET Renewable Power Generation Engineering and Technology, vol. 2, 2008, pp. 123-138.

10. A. Grauers, "Efficiency of three wind energy generator systems," IEEE Transactions on Energy Conversion, vol. 11, 1996, pp. 650-657.

11. A.D. Hansen and G. Michalke, "Modelling and Control of Variable -speed Multi-pole Permanent Magnet Synchronous Generator Wind Turbine,” Wind Energy, vol. 11, 2008, pp. 537-554.

12. L.M. Fernandez, C. a Garcia, and F. Jurado, "Operating capability as a PQ/PV node of a direct-drive wind turbine based on a permanent magnet synchronous generator," Renewable Energy, vol. 35, Jun. 2010, pp. 1308-1318.

13. S. Achilles and M. Poller, "Direct Drive Synchronous Machine Models for Stability Assessment of Wind Farms," pp. 1-9. Available from, http://www.digsilent.de/Consulting/Publications/DirectDrive_Modeling.pdf>. 
14. Y. Kazachkov, \& R. Voelzke, "Modeling wind farms for power system load flow and stability studies”. 2005 IEEE Russia Power Tech, pp. 1-8.

15. R. Ranjan, B. Venkatesh, A. Chaturvedi, and D. Das (2004) 'Power Flow Solution of Three-Phase Unbalanced Radial Distribution Network', Electric Power Components and Systems, vol. 32, no. 4, pp 421-433

16. A. E. Feijóo and J. Cidras, "Modeling of Wind Farms in the Load flow Analysis", IEEE Transactions on Power Systems, vol. 15, no. 1, Feb. 2000, pp. 110-115.

17. U. Eminoglu, "Modeling and application of wind turbine generating system (WTGS) to distribution systems", Renewable Energy, vol. 34, 2009, pp.2474-2483.

18. A. Feijóo, “On PQ Models for Asynchronous Wind Turbines”, IEEE Transactions on Power Systems, vol. 24, No. 4, Nov. 2009, pp.1890-1891.

19. J. F. M. Padrón and A. E. Feijóo Lorenzo, "Calculating Steady-State Operating Conditions for Doubly-Fed Induction Generator Wind Turbines", IEEE Transactions on Power Systems, vol. 25, no. 2, May 2010, pp. 922-928.

20. H. Chen, J. Chen, D. Shi, and X. Duan, "Power flow study and voltage stability analysis for distribution systems with distributed generation," 2006 IEEE Power Engineering Society General Meeting, IEEE, 2006.

21. G. Coath and M. Al-Dabbagh, "Effect of Steady-State Wind Turbine Generator Models on Power Flow Convergence and Voltage Stability Limit," Australasian Universities Power Engineering Conference, Hobart: 2005.

22. M. Ding, X. Guo, and Z. Zhang, "Three Phase Power Flow for Weakly Meshed Distribution Network with Distributed Generation," 2009 Asia-Pacific Power and Energy Engineering Conference, 2009, pp. 1-7.

23. K. Divya and P. Rao, "Models for wind turbine generating systems and their application in load flow studies," Electric Power Systems Research, vol. 76, Jun. 2006, pp. 844-856.

24. S.M. Moghaddas-Tafreshi and E. Mashhour, "Distributed generation modeling for power flow studies and a three-phase unbalanced power flow solution for radial distribution systems considering distributed generation," Electric Power Systems Research, vol. 79, Apr. 2009, pp. 680-686.

25. M. Zhao, Z. Chen, and F. Blaabjerg, "Load flow analysis for variable speed offshore wind farms," IET Renewable Power Generation, vol. 3, 2009, pp. 120-132. 
26. F. Blaabjerg and Z. Chen, "Power Electronics for Modern Wind Turbines", $1^{\text {st }}$ ed. Morgan \& Claypool, 2006.

27. T. Burton, D. Sharpe, N. Jenkins, E. Bossanyi, “Wind Energy Hand Book”, John Wiley \& Sons, 2001, pp. 6-45.

28. Kundur P. Power System Stability and Control, EPRI. McGraw-Hill: New York, 1994. pp.54.

29. An Introduction to Electrical Machines and Transformers - G. McPherson \& R.D, Laramore $2^{\text {nd }}$ ed. John Wiley \& Sons-pp.47.

30. E. Muljadi, S. Drouilhet, R. Holz, and V. Gevorgian, "Analysis of permanent magnet generator for wind power battery charging," Thirty-First IAS Annual Meeting \& Industry Applications Conference, San Diego, CA: 1996, pp. 541-548.

31. A. de V. Jaén, E. Acha, and A.G. Expósito, "Voltage Source Converter Modeling for Power System State Estimation: STATCOM and VSC-HVDC," IEEE Transactions on Power Systems, vol. 23, 2008, pp. 1552-1559.

32. K. Kretschmar and H.-P. Nee, "Analysis of the Efficiency and Suitability of Different Converter Topologies for PM Integral Motors," Proceedings of the Australian Universities Power Engineering Conference, Perth, 2001, pp 519-525.

33. Angeles-Camacho, C., Tortelli, O., Acha, E., \& Fuerte-Esquivel, C. (2003). Inclusion of a high voltage DC-voltage source converter model in a Newton-Raphson power flow algorithm. IEE Proceedings - Generation, Transmission and Distribution, vol. 150(6), 691-696.

34. F. Al Jowder and B.T. Ooi, "VSC-HVDC station with SSSC characteristics," IEEE 34th Annual Conference on Power Electronics Specialist. PESC '03, 2003, pp. 1785-1791.

35. N. Mohan, T. M. Undeland, and W. P. Robbins, Power Electronics: Converters, Applications and Design, 3rd ed. John Wiley \& Sons, 2002.

36. C. Kim, V. K. Sood, G. Jang, S. Lim, and S. Lee, HVDC Transmission: Power Conversion Applications in Power Systems, $1^{\text {st }}$ ed. John Wiley \& Sons, 2009. pp. 329340.

37. The Mathworks Inc., "Simpower system ${ }^{T M} 5$ Reference", 2009, pp.2-17-2- 30, 2-881-2292. 
38. W. H. Kersting, "Distribution System Modeling and Analysis", second edition, CRC Press, 2007

39. IEEE PES, "Distribution Test feeders",-37 bus feeder, http://ewh.ieee.org/soc/pes/dsacom/testfeeders/index.html 


\section{Appendix A}

\section{Data Set for the Type 4 PMSG WECS Model}

\section{Table A.1: Wind Turbine data set}

\begin{tabular}{|c|c|}
\hline Wind Turbine Nominal Power, $\mathrm{P}_{\mathrm{n}}$ & $2 \mathrm{MW}$ \\
\hline Nominal Wind Speed, $\omega_{n}$ & $11 \mathrm{~m} / \mathrm{s}$ \\
\hline Grid Connection Voltage $(\mathrm{LL})$ & $575 \mathrm{~V}(\mathrm{RMS})$ \\
\hline
\end{tabular}

Table A.2: Generator data set

\begin{tabular}{|c|c|}
\hline Nominal Power, $\mathrm{P}_{\mathrm{n}}$ & $2.22 \mathrm{MVA}$ \\
\hline Nominal frequency, $\mathrm{f}_{\mathrm{n}}$ & $60 \mathrm{~Hz}$ \\
\hline Nominal Voltage $(\mathrm{LL}), \mathrm{V}_{\mathrm{n}}$ & $730 \mathrm{~V}(\mathrm{RMS})$ \\
\hline Number of Pole-pairs, $\mathrm{p}$ & 1 \\
\hline Stator Resistance, $\mathrm{R}_{\mathrm{s}}$ & $0.006 \mathrm{pu}$ \\
\hline Synchronous Reactance, $\mathrm{X}_{\mathrm{s}}$ & $1.305 \mathrm{pu}$ \\
\hline
\end{tabular}

Table A.3: Converters data set

\begin{tabular}{|c|c|}
\hline Rectifier Impedance & $6.58 \mathrm{~m} \Omega$ \\
\hline Boost Converter Impedance & $5.14 \mathrm{~m} \Omega$ \\
\hline Inverter Impedance & $1.8 \mathrm{~m} \Omega$ \\
\hline
\end{tabular}




\section{Appendix B \\ Load Models Description with General Equations}

In distribution systems, loads can be wye (star) connected or delta connected and threephase, two-phase, or single-phase with unbalanced nature. These can be modeled as:

1. Constant real and reactive power (Constant PQ)

2. Constant current

3. Constant Impedance

4. Any combination of above.

Figure B.1 shows a generic delta connected load. In the IEEE-37 test feeder system, all loads are delta connected. Therefore, only delta connected loads modeling is described here.

These load models are used in the iterative process of load-flow algorithm, where load voltages are initially assumed.

For all loads, the line currents entering the load are required in order to perform the load-flow analysis.

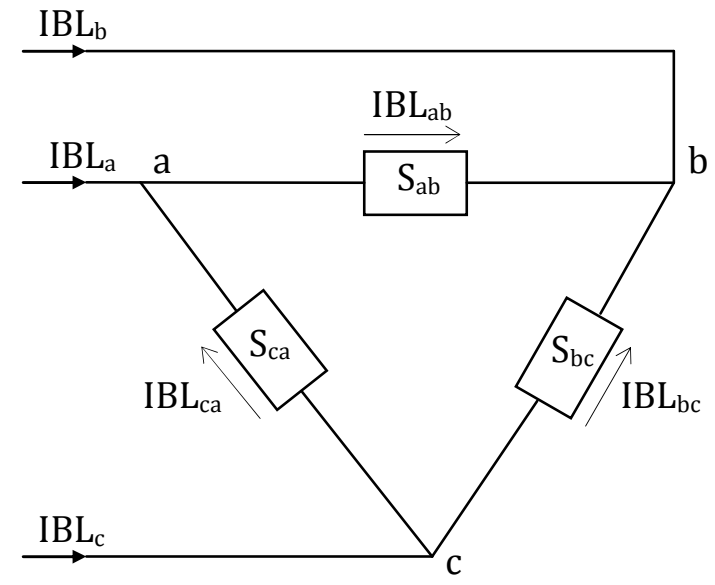

Figure B.1: Delta connected load 
The general equations of current computations for each model are [38]:

\begin{tabular}{|l|l|}
\hline \multicolumn{1}{|c|}{ Model } & \multicolumn{1}{c|}{ Computation of current } \\
\hline $\begin{array}{l}\text { Constant PQ } \\
\text { (D-PQ) } \\
\text { (Type-001) }\end{array}$ & $\begin{array}{l}I B L_{L L}=\left(\frac{S_{L L}}{V_{L L}}\right)^{*}=\frac{\left|S_{L L}\right|}{\left|V_{L L}\right|}<\delta_{L L}-\theta_{L L}=\left|I B L_{L L}\right| \angle \alpha_{L L} \\
\text { The line to line voltages will change after each iteration and as a result the }\end{array}$ \\
\hline $\begin{array}{l}\text { Constant I } \\
\text { (D-I) } \\
\text { (Type-002) }\end{array}$ & $\begin{array}{l}\text { Magnitudes of currents are computed similarly to those in the constant PQ } \\
\text { model and held constant. } \\
\text { Meanwhile, the angle of the voltage changes after each iteration. } \\
\text { This keeps the power factor of the load constant. }\end{array}$ \\
\hline $\begin{array}{l}\text { Constant Z } \\
\text { (D-Z) } \\
\text { (Type-003) }\end{array}$ & $\begin{array}{l}\text { Constant load impedance, } Z_{L L}=\frac{\left|V_{L L}\right|^{2}}{S_{L L}^{*}}=\frac{\left|V_{L L}\right|^{2}}{\left|S_{L L}\right|}=\left|Z_{L L}\right| \angle \theta_{L L} \\
\text { The delta load IBL is a function of the constant load impedances and are } \\
\text { given by } \\
I B L_{L L}=\frac{V_{L L}}{Z_{L L}}=\frac{\left|V_{L L}\right|}{\left|Z_{L L}\right|}<\delta_{L L}-\theta_{L L}=\left|I B L_{L L}\right| \angle \alpha_{L L} \\
V_{L L} \text { changes after each iteration until convergence is achieved. }\end{array}$ \\
\hline
\end{tabular}




\section{Appendix C}

\section{Computation of a, b, c, d, A, B Parameters of Series Feeder Components}

The description of the test system includes the voltage regulator, transformer and line segments. Therefore, the parameters a, b, c, d, A, B can be obtained by using the following equations [38] and Matlab programming codes as described in Appendix D.

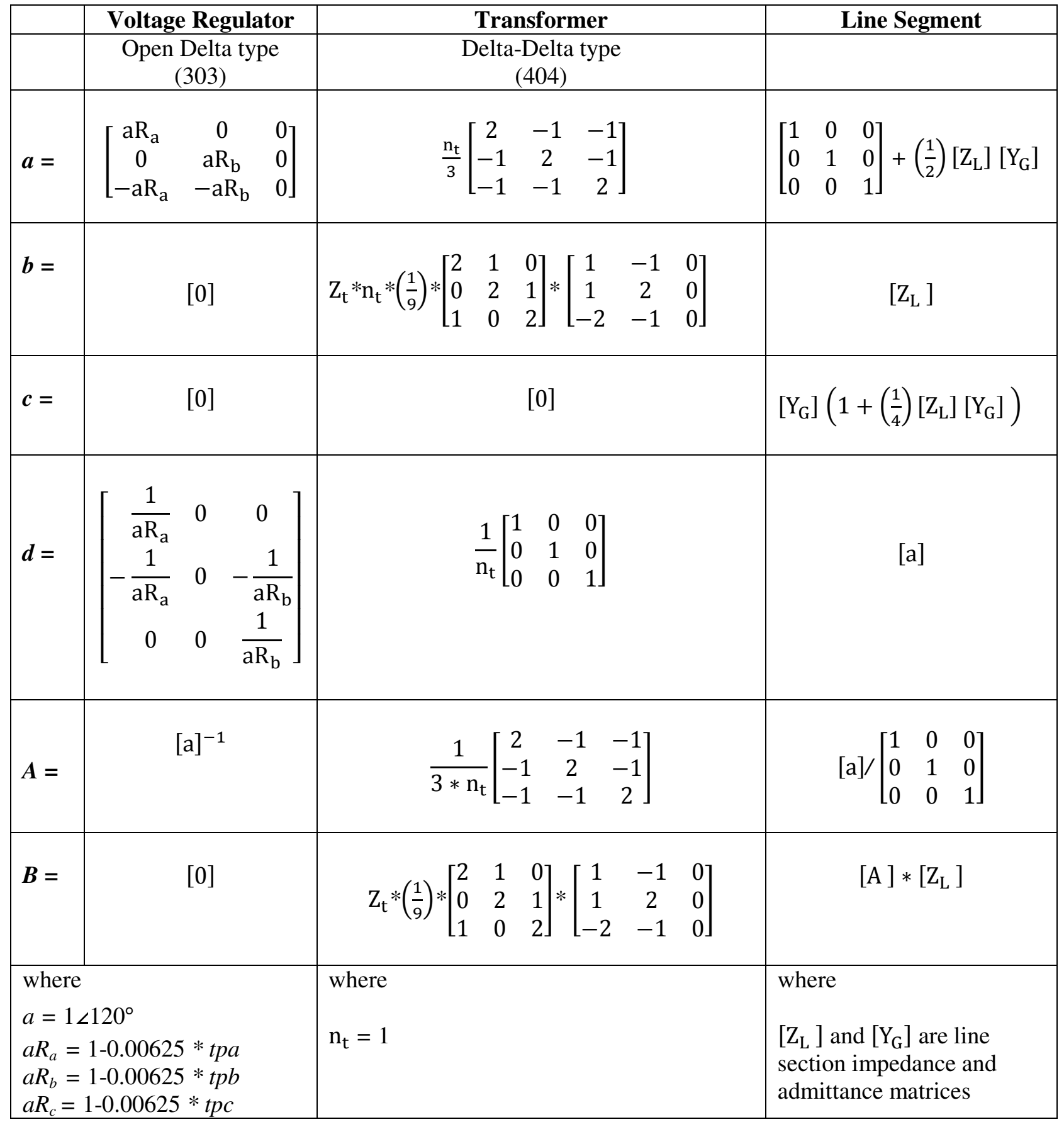




\section{Appendix D}

\section{MATLAB Code for Load Flow}

\section{Input Data File}

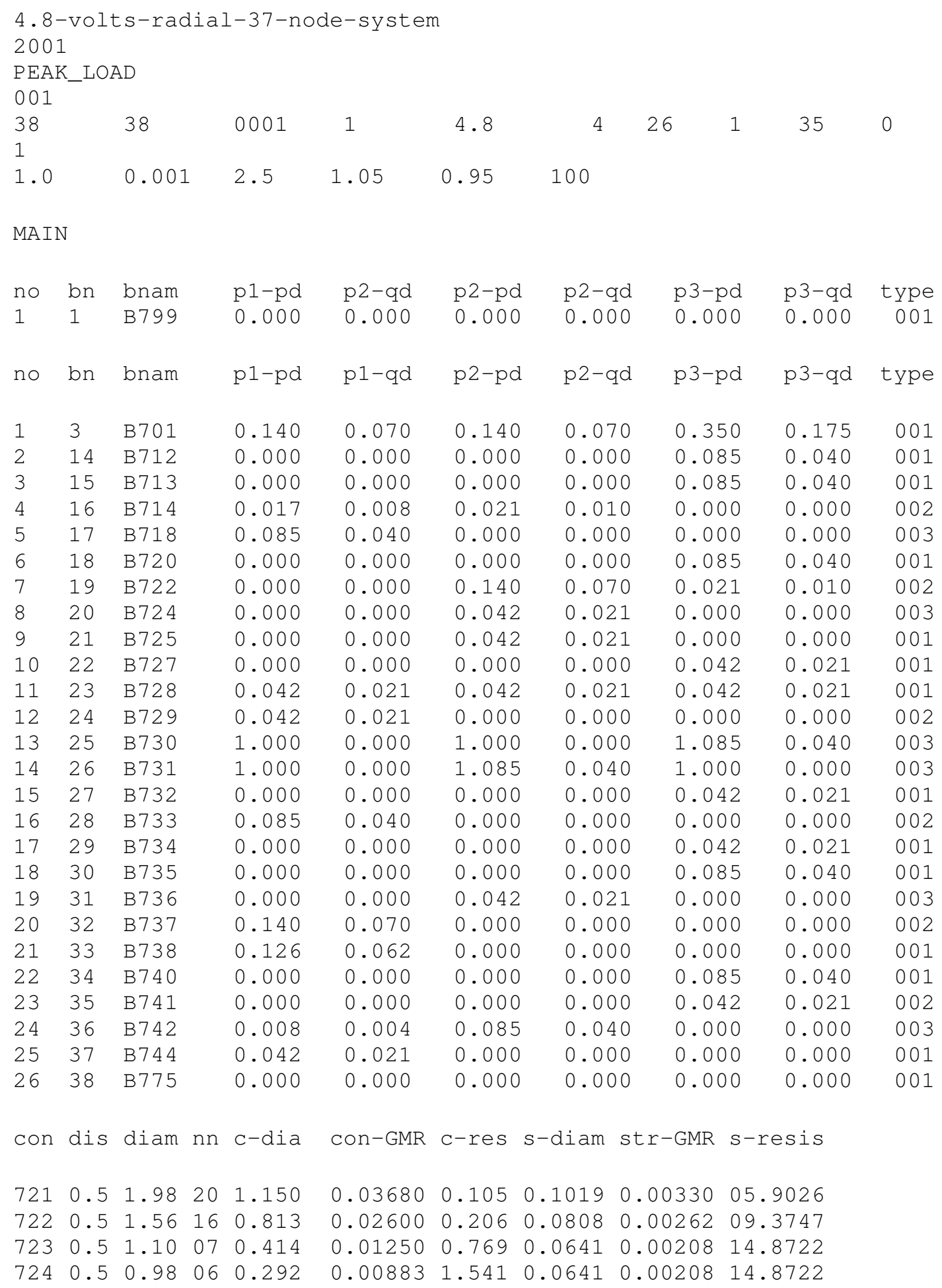




\begin{tabular}{|c|c|c|c|c|c|c|}
\hline $\mathrm{fb}$ & tb & tpa & & & tpc con & \\
\hline 1 & 2 & 6.699843 & 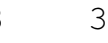 & 02439024 & 303 & \\
\hline $\mathrm{fb}$ & tb & vllh & vlll & r & $\mathrm{x}$ & rat \\
\hline 11 & 38 & 4.8 & 0.575 & 0.0009 & 0.0181 & 2.5 \\
\hline
\end{tabular}

$\begin{array}{lllllll}\text { no } & \text { fb } & \text { tb } & \text { lengt } & \text { zer } & \text { pos } & \text { con } \\ 3 & 2 & 3 & 1.850 & 0.0 & 0.0 & 721 \\ 4 & 3 & 4 & 0.960 & 0.0 & 0.0 & 722 \\ 5 & 4 & 5 & 1.320 & 0.0 & 0.0 & 722 \\ 6 & 5 & 25 & 0.600 & 0.0 & 0.0 & 723 \\ 7 & 25 & 11 & 0.200 & 0.0 & 0.0 & 723 \\ 8 & 11 & 10 & 0.320 & 0.0 & 0.0 & 723 \\ 9 & 10 & 28 & 0.320 & 0.0 & 0.0 & 723 \\ 10 & 28 & 29 & 0.560 & 0.0 & 0.0 & 723 \\ 11 & 29 & 32 & 0.640 & 0.0 & 0.0 & 723 \\ 12 & 32 & 33 & 0.400 & 0.0 & 0.0 & 723 \\ 13 & 33 & 13 & 0.400 & 0.0 & 0.0 & 723 \\ 14 & 13 & 35 & 0.400 & 0.0 & 0.0 & 723 \\ 15 & 4 & 7 & 0.400 & 0.0 & 0.0 & 724 \\ 16 & 7 & 36 & 0.320 & 0.0 & 0.0 & 724 \\ 17 & 4 & 15 & 0.360 & 0.0 & 0.0 & 723 \\ 18 & 15 & 6 & 0.520 & 0.0 & 0.0 & 723 \\ 19 & 6 & 18 & 0.800 & 0.0 & 0.0 & 723 \\ 20 & 18 & 8 & 0.600 & 0.0 & 0.0 & 723 \\ 21 & 8 & 21 & 0.280 & 0.0 & 0.0 & 724 \\ 22 & 5 & 22 & 0.240 & 0.0 & 0.0 & 724 \\ 23 & 22 & 37 & 0.280 & 0.0 & 0.0 & 723 \\ 24 & 37 & 24 & 0.280 & 0.0 & 0.0 & 724 \\ 25 & 6 & 16 & 0.080 & 0.0 & 0.0 & 724 \\ 26 & 16 & 17 & 0.520 & 0.0 & 0.0 & 724 \\ 27 & 18 & 9 & 0.920 & 0.0 & 0.0 & 724 \\ 28 & 9 & 20 & 0.760 & 0.0 & 0.0 & 724 \\ 29 & 9 & 19 & 0.120 & 0.0 & 0.0 & 724 \\ 30 & 7 & 14 & 0.240 & 0.0 & 0.0 & 724 \\ 31 & 10 & 27 & 0.320 & 0.0 & 0.0 & 724 \\ 32 & 11 & 26 & 0.600 & 0.0 & 0.0 & 723 \\ 33 & 29 & 12 & 0.520 & 0.0 & 0.0 & 724 \\ 34 & 12 & 30 & 0.200 & 0.0 & 0.0 & 724 \\ 35 & 12 & 31 & 1.280 & 0.0 & 0.0 & 724 \\ 36 & 13 & 34 & 0.200 & 0.0 & 0.0 & 724 \\ 37 & 37 & 23 & 0.200 & 0.0 & 0.0 & 724\end{array}$

\section{Main File to Read the Data and all Function Files}

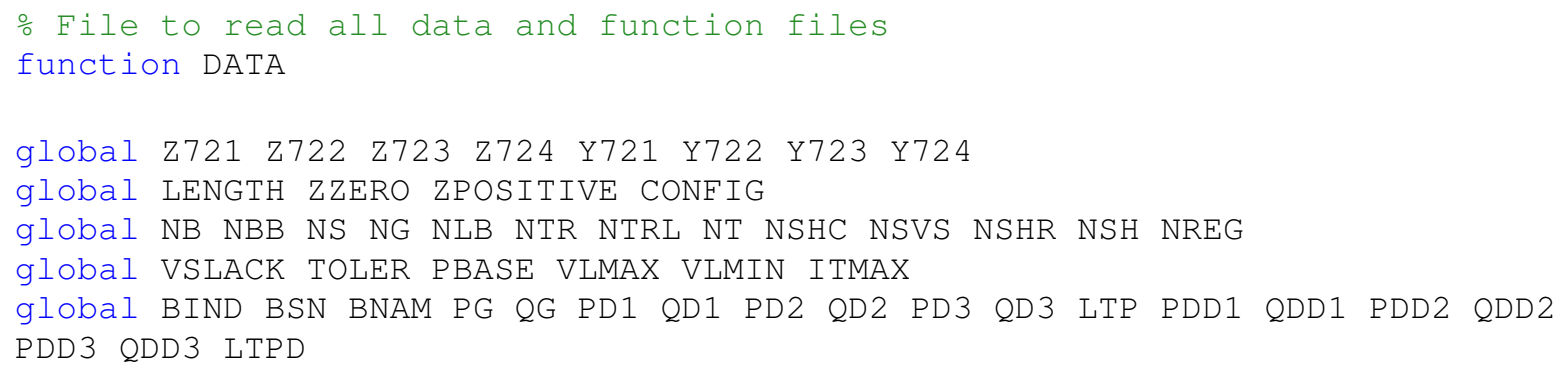


global TRNO FB TB VLLH VLLL R X PRAT

global TPA TPB TPC

global VBASE

global ifp 은 file pointers

temp1 = input ('Input File Name:', 'S' );

ifp $=$ fopen $($ templ, 'r');

temp $=$ fscanf $\left(\mathrm{ifp}, \prime^{\prime} \circ \mathrm{s}^{\prime},[1]\right)$;

temp $=$ fscanf (ifp, ' $\left.\% \mathrm{~s}^{\prime},[1]\right)$;

temp $=$ fscanf (ifp, ' $\left.\% \mathrm{~s}^{\prime},[1]\right)$;

temp $=$ fscanf (ifp, '\% ', [1]);

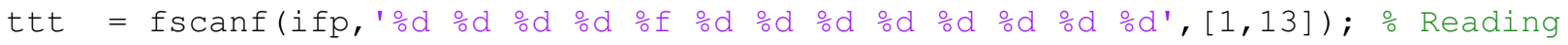

the following data

$\mathrm{NB}=$ ttt $(1) ; \quad \div$ Number of Buses

$\mathrm{NBB}=\operatorname{ttt}(2) ;$

$\mathrm{NS}=$ ttt $(3) ; \quad \%$ Slack Bus Number

$\mathrm{NG}=\operatorname{ttt}(4) ; \quad \circ$ Number of Generators

VBASE $=$ ttt (5); $\%$ Base Voltage in $\mathrm{kV}$

$\mathrm{NCON}=\operatorname{ttt}(6) ; \quad \%$ Number of Line Configurations

$\mathrm{NLB}=$ ttt $(7) ; \quad \%$ Number of Load Buses

NTR $=$ ttt $(8) ; \quad \circ$ Number of Transformers

NTRL $=$ ttt $(9) ; \quad \div$ Number of Transmission Lines

NSHC $=$ ttt $(10) ;$ Number of Shunt Capacitors

NSVS $=$ ttt (11); $\frac{\circ}{\circ}$ Number of Switchable Capacitors

NSHR $=$ ttt (12); $\frac{\circ}{0}$ Number of Shunt Reactors

$\mathrm{NREG}=$ ttt $(13) ;$ Number of Regulators

Adding Components/Lines

$\mathrm{NT}=\mathrm{NTR}+\mathrm{NTRL}+\mathrm{NREG} ; \quad$ \% Number of Total Lines/Components

$\mathrm{NSH}=\mathrm{NSHC}+\mathrm{NSVS}+\mathrm{NSHR} ; \quad \frac{\circ}{\circ}$ Number of Shunts

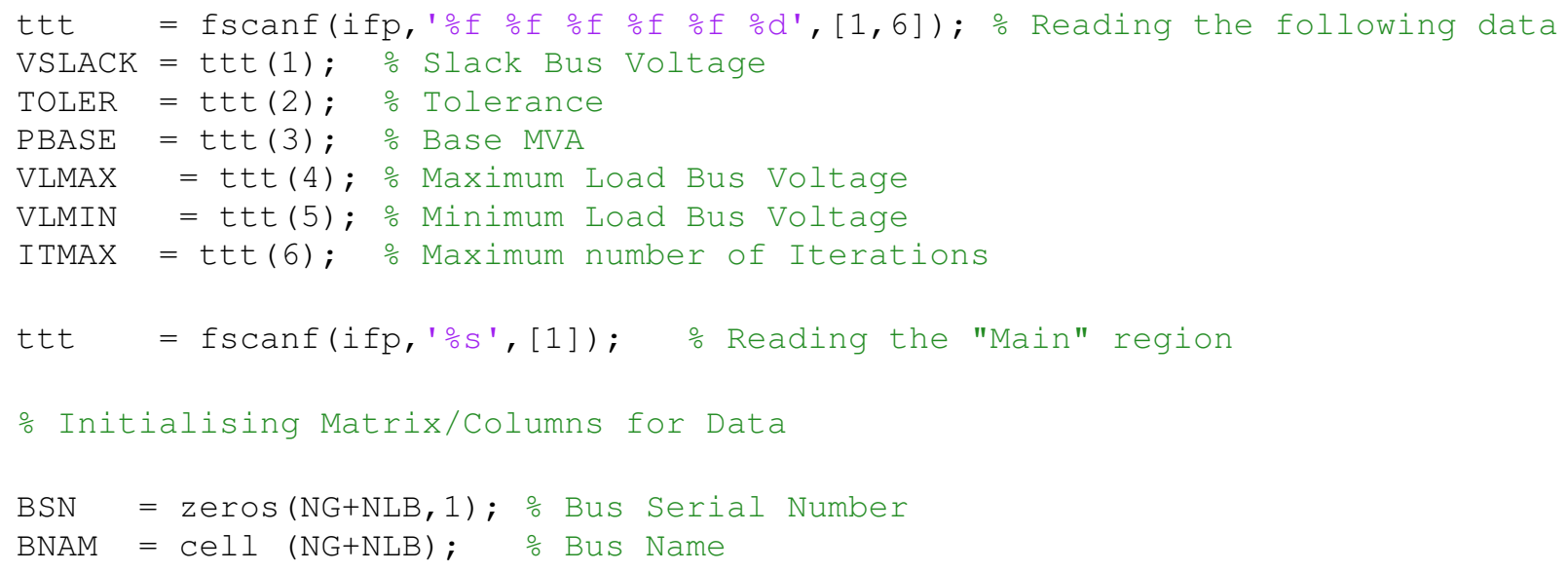




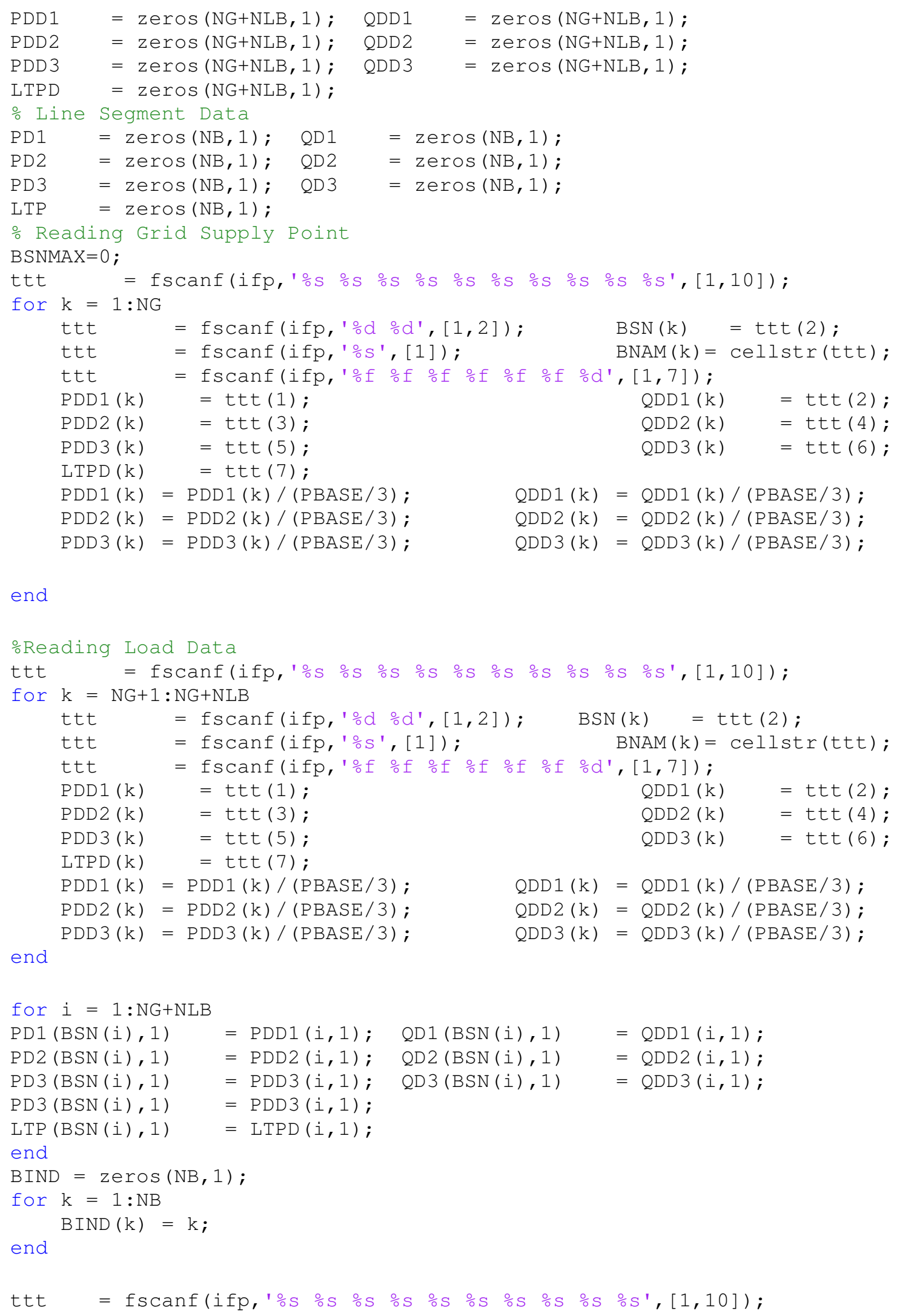




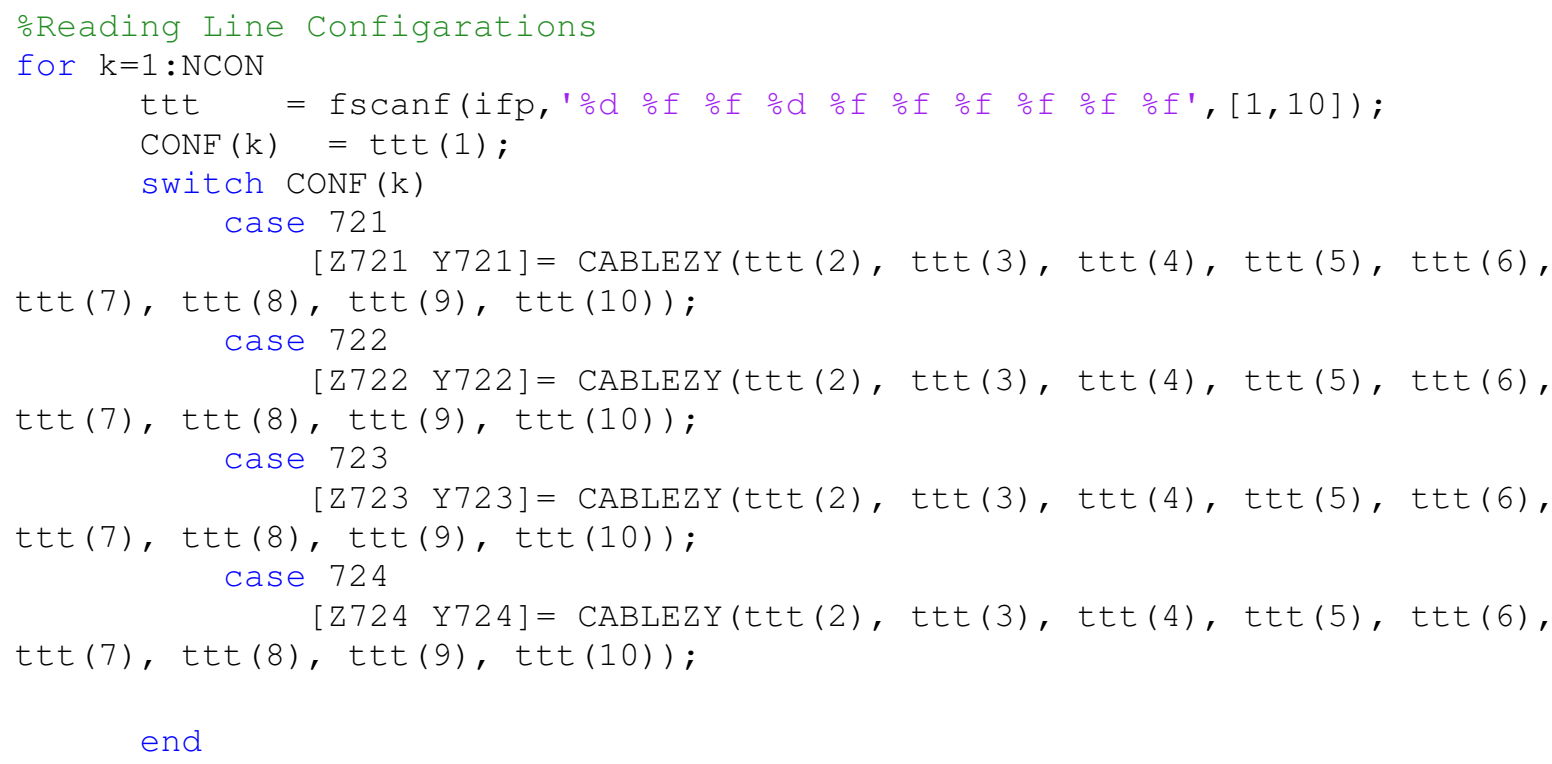

end 


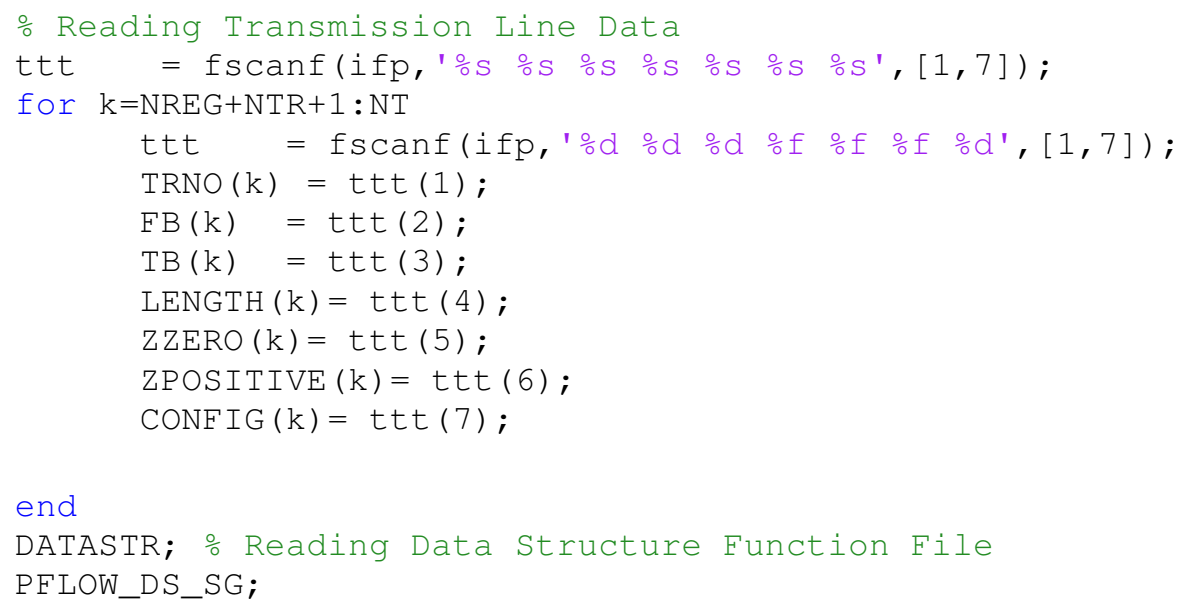

end

DATASTR; 을 Reading Data Structure Function File PFLOW_DS_SG;

\section{Function to Compute Line Impedance and Admittance matrices}

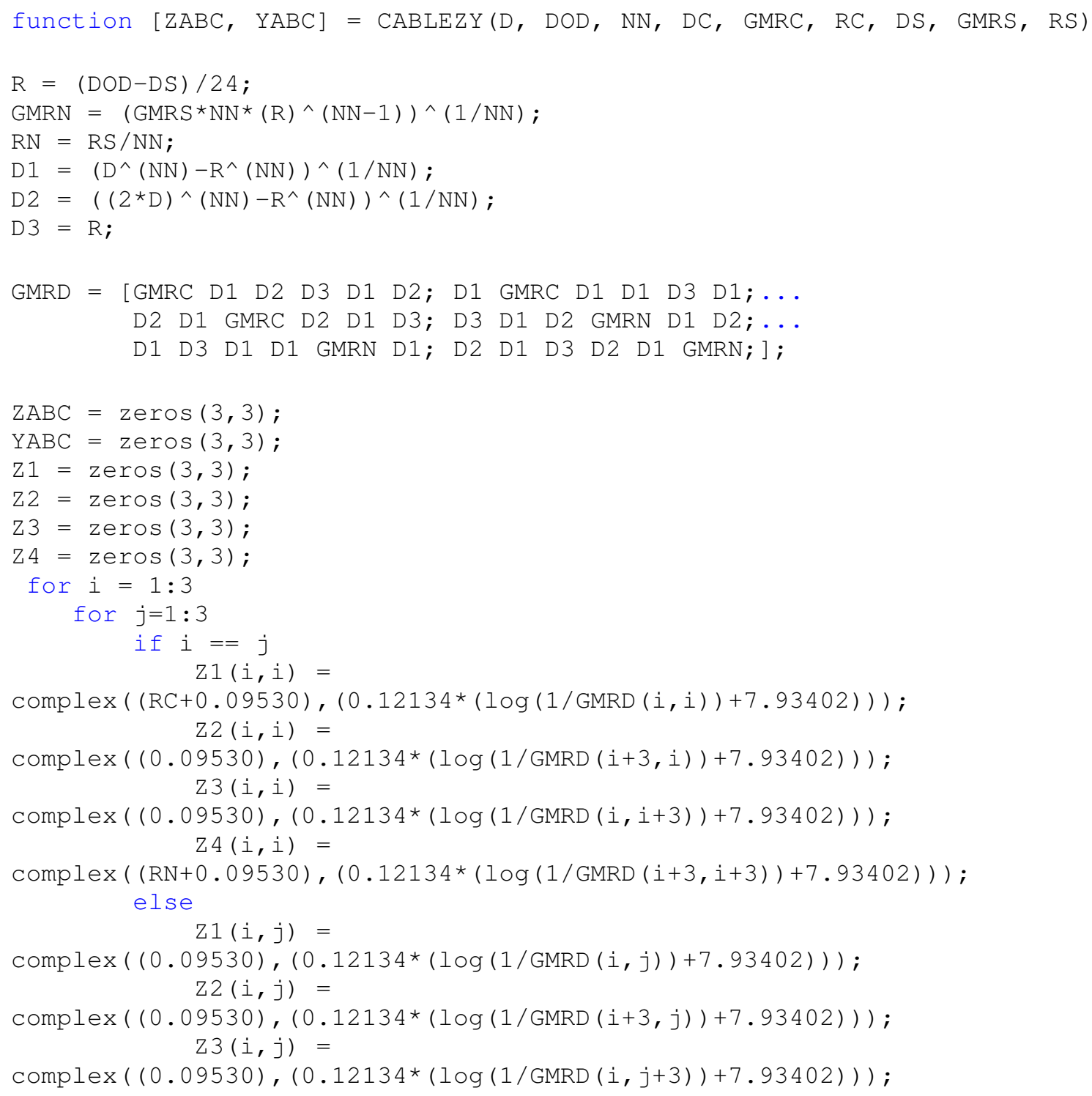




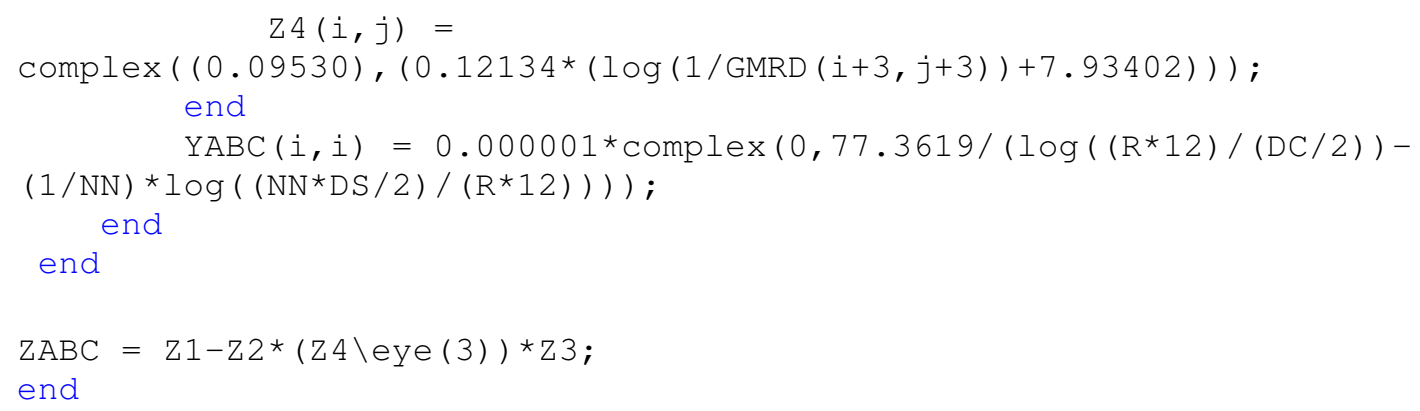

Function to Compute a, b, c, d, A, B parameters of Line

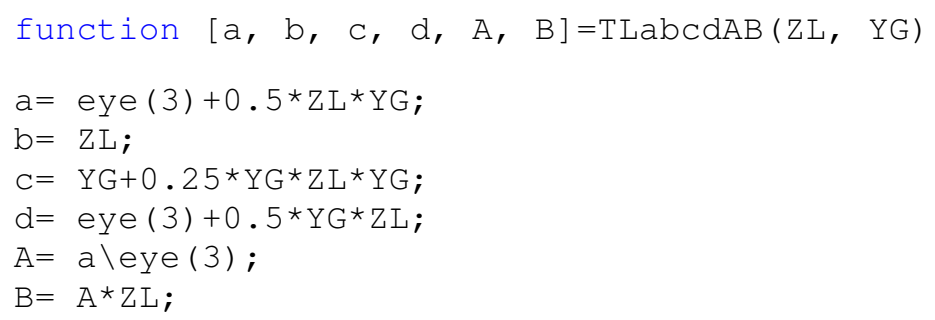

\section{Function to Compute a, b, c, d, A, B parameters of Transformer}

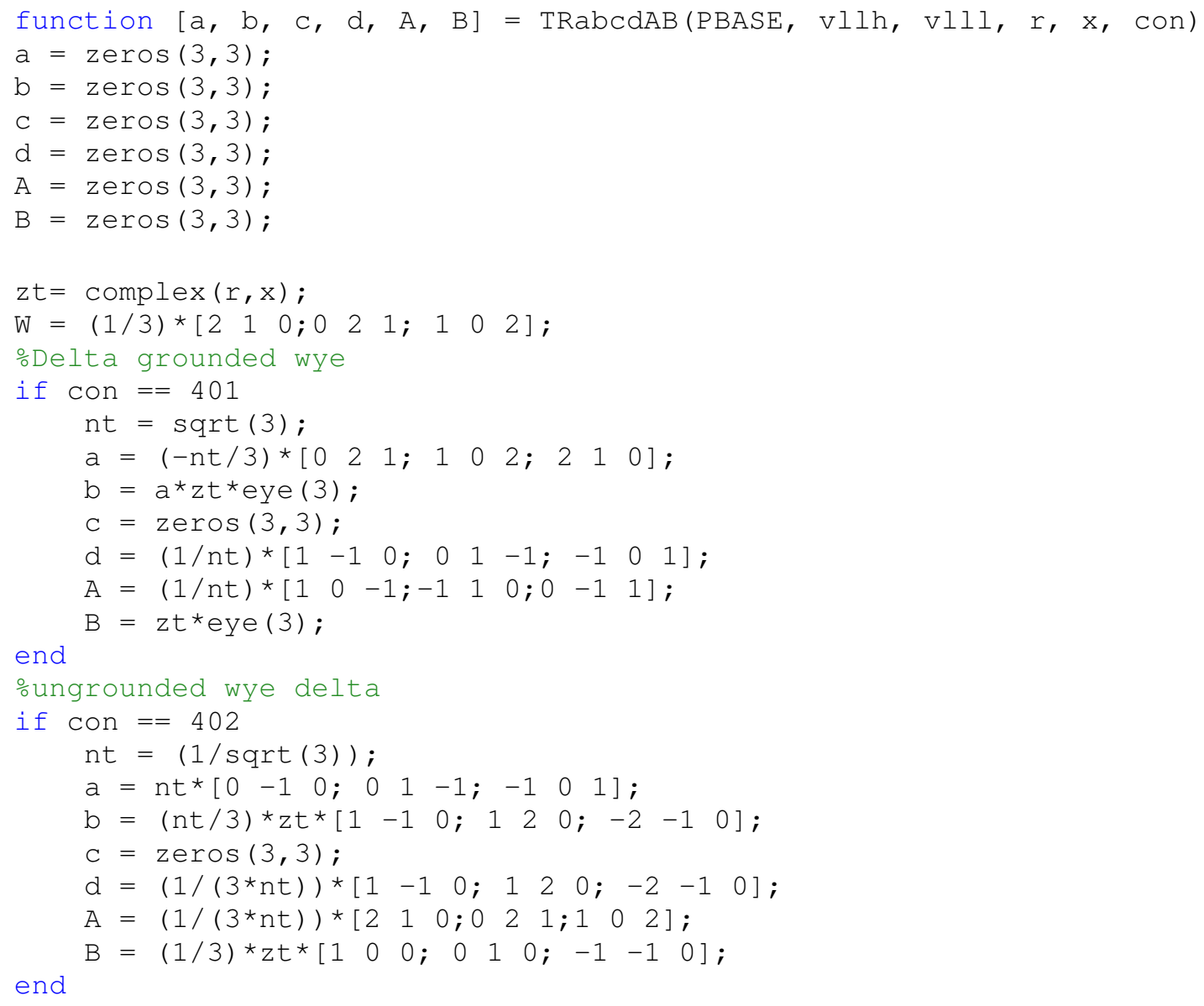




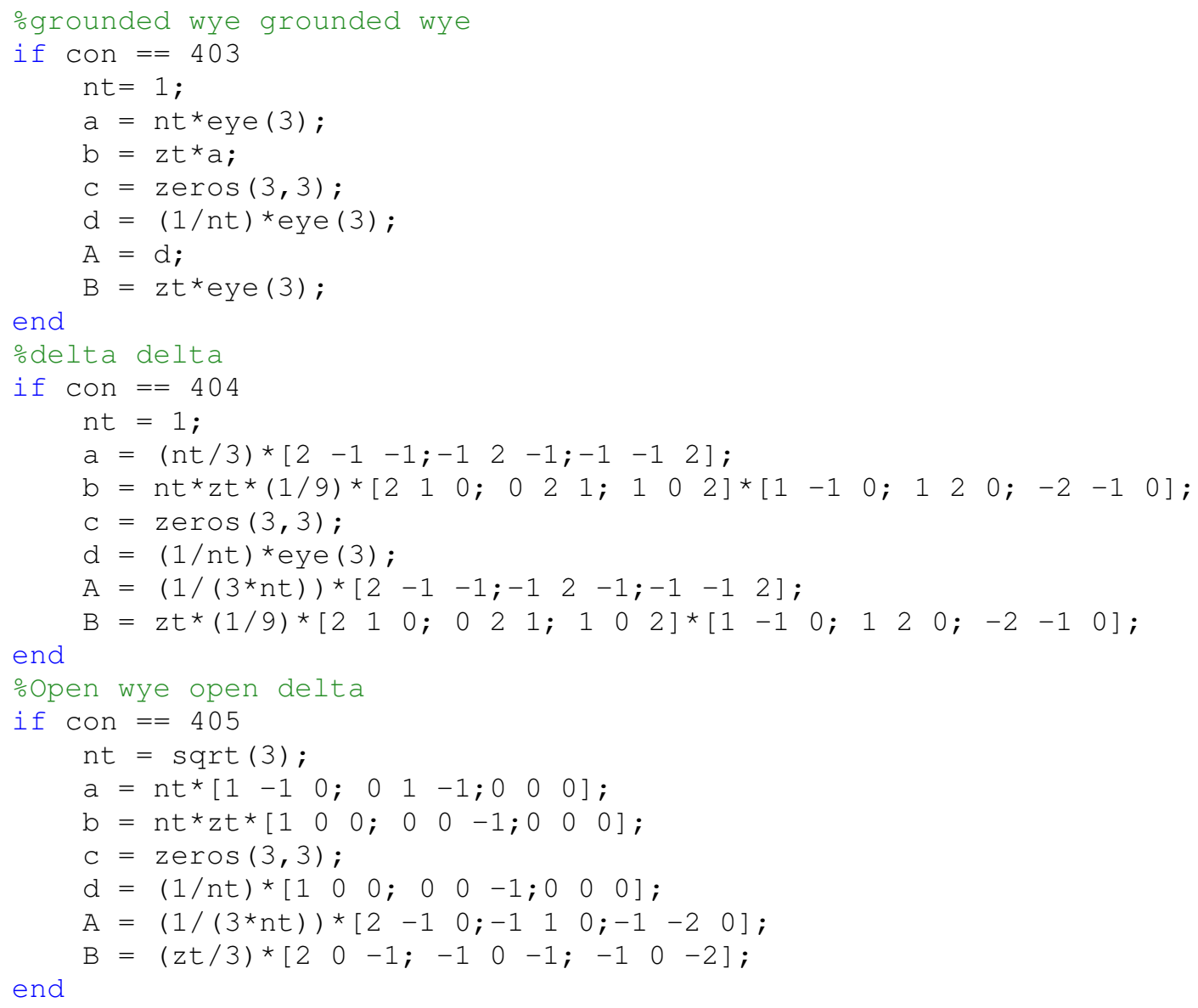

\section{Function to Compute a, b, c, d, A, B parameters of Voltage Regulator}

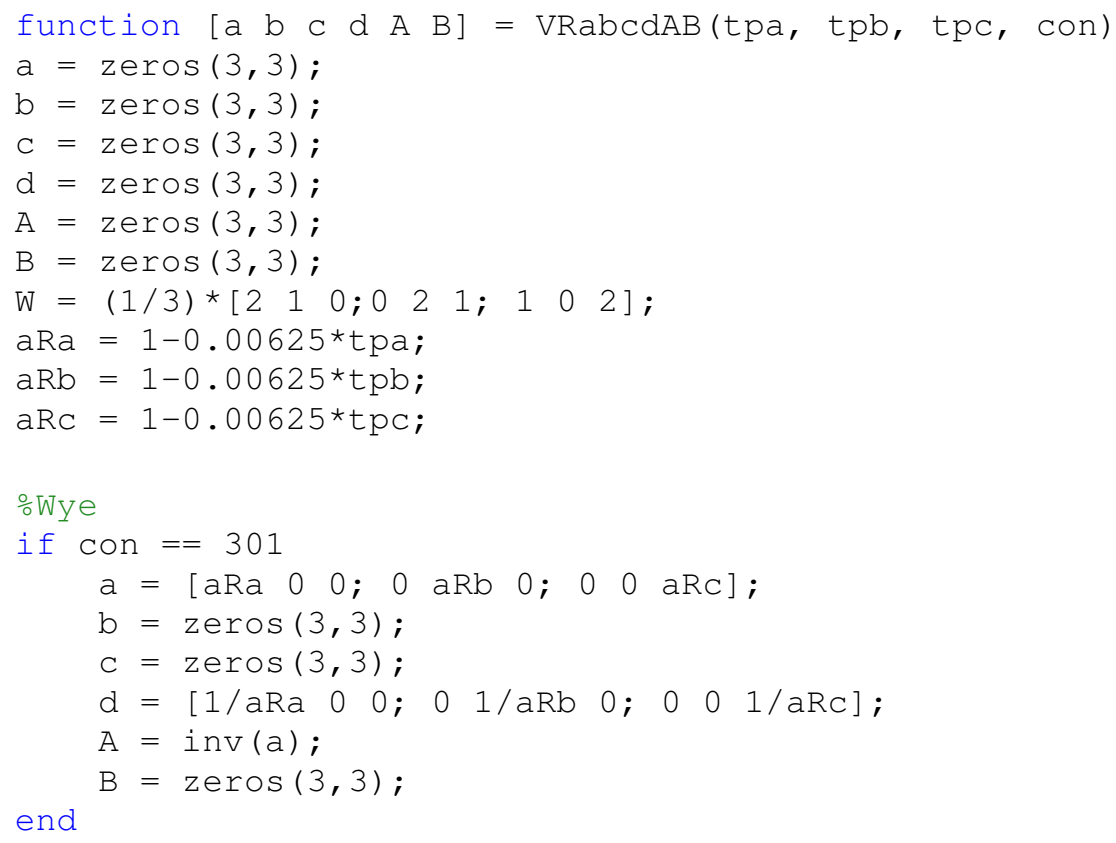




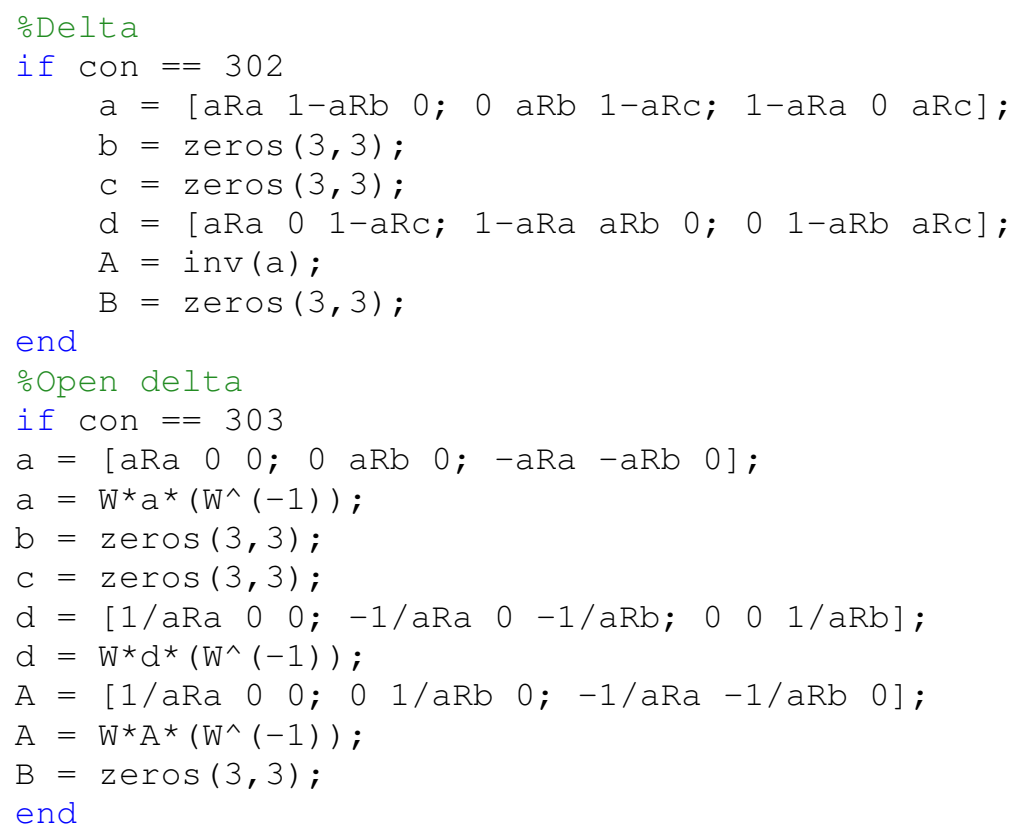

\section{Ladder iterative Algorithm for Load Flow}

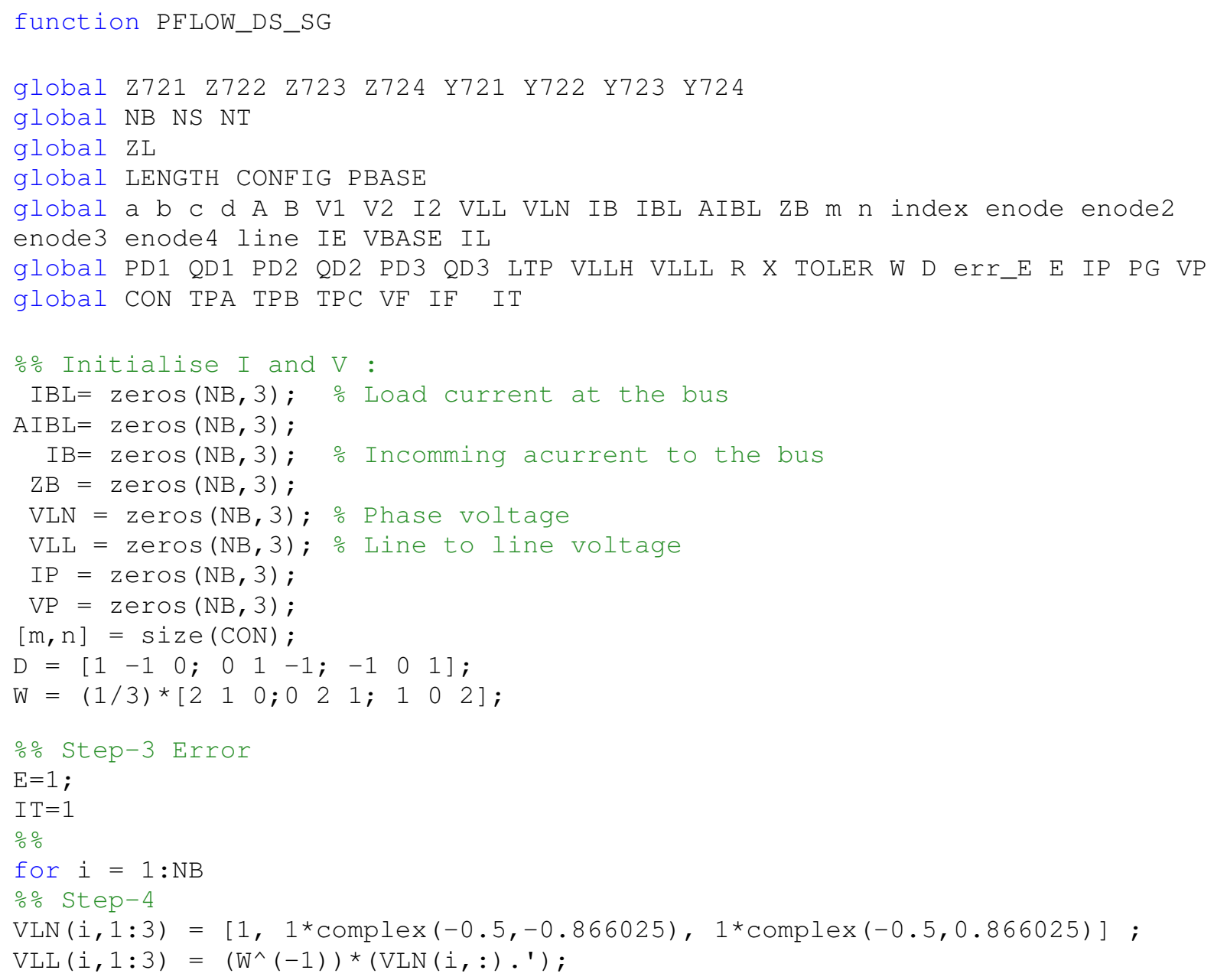




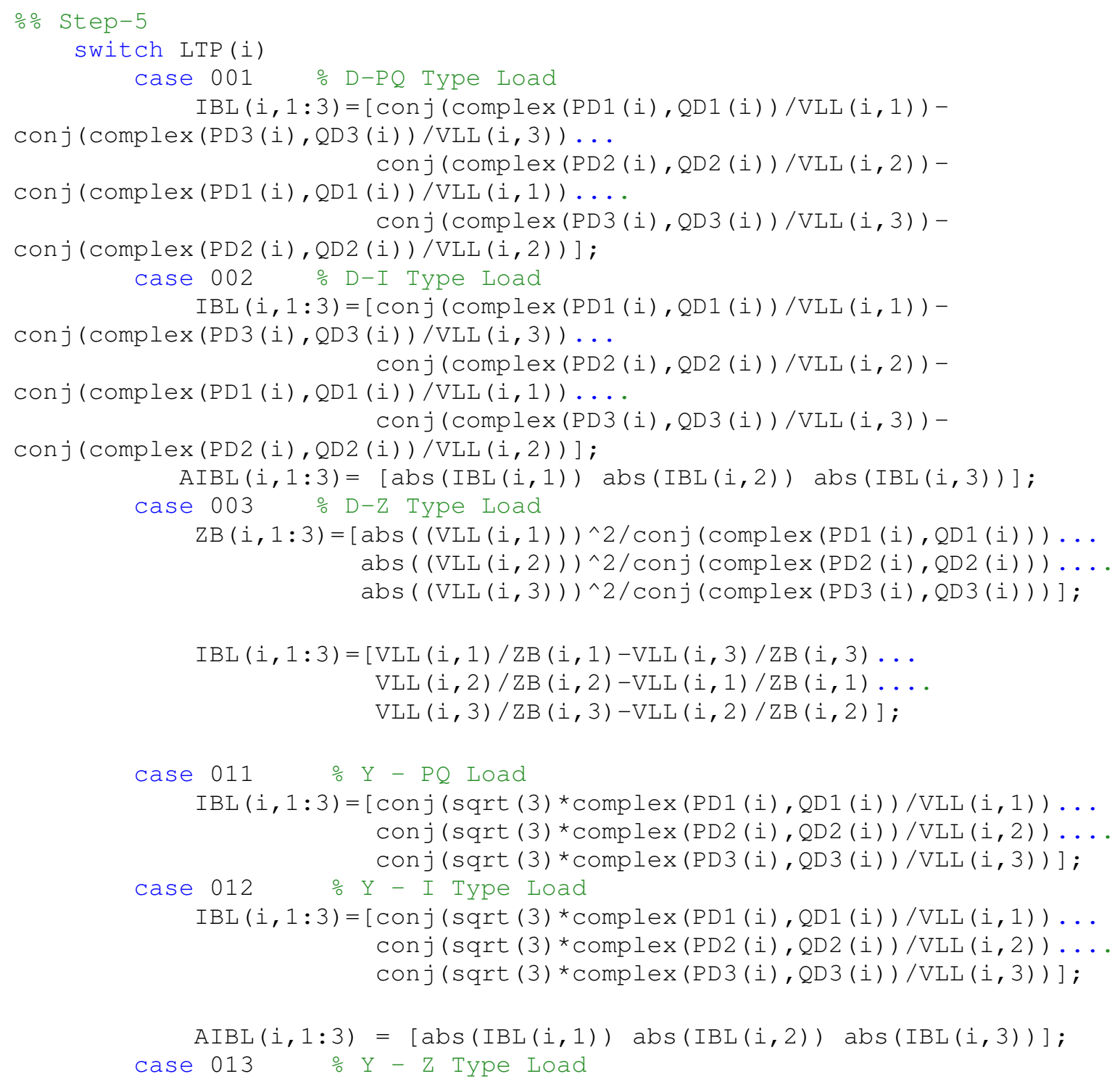

end

end

$\mathrm{IB}=\mathrm{IBL}$;

응 Step-6 FORWARD SWEEP

while $\mathrm{IT}<100$ \&\& abs $(\mathrm{E})>\mathrm{TOLER} * 1$

$\mathrm{IL}=\operatorname{zeros}(\mathrm{NT}, 3) ; \quad \mathrm{IE}=\operatorname{zeros}(\mathrm{NT}, 1) ; \mathrm{V} 2=\operatorname{zeros}(3,3) ; \mathrm{I} 2=\operatorname{zeros}(3,3) ; \mathrm{PG}=$ zeros $(\mathrm{NB}, 3)$;

enode $=0$; 


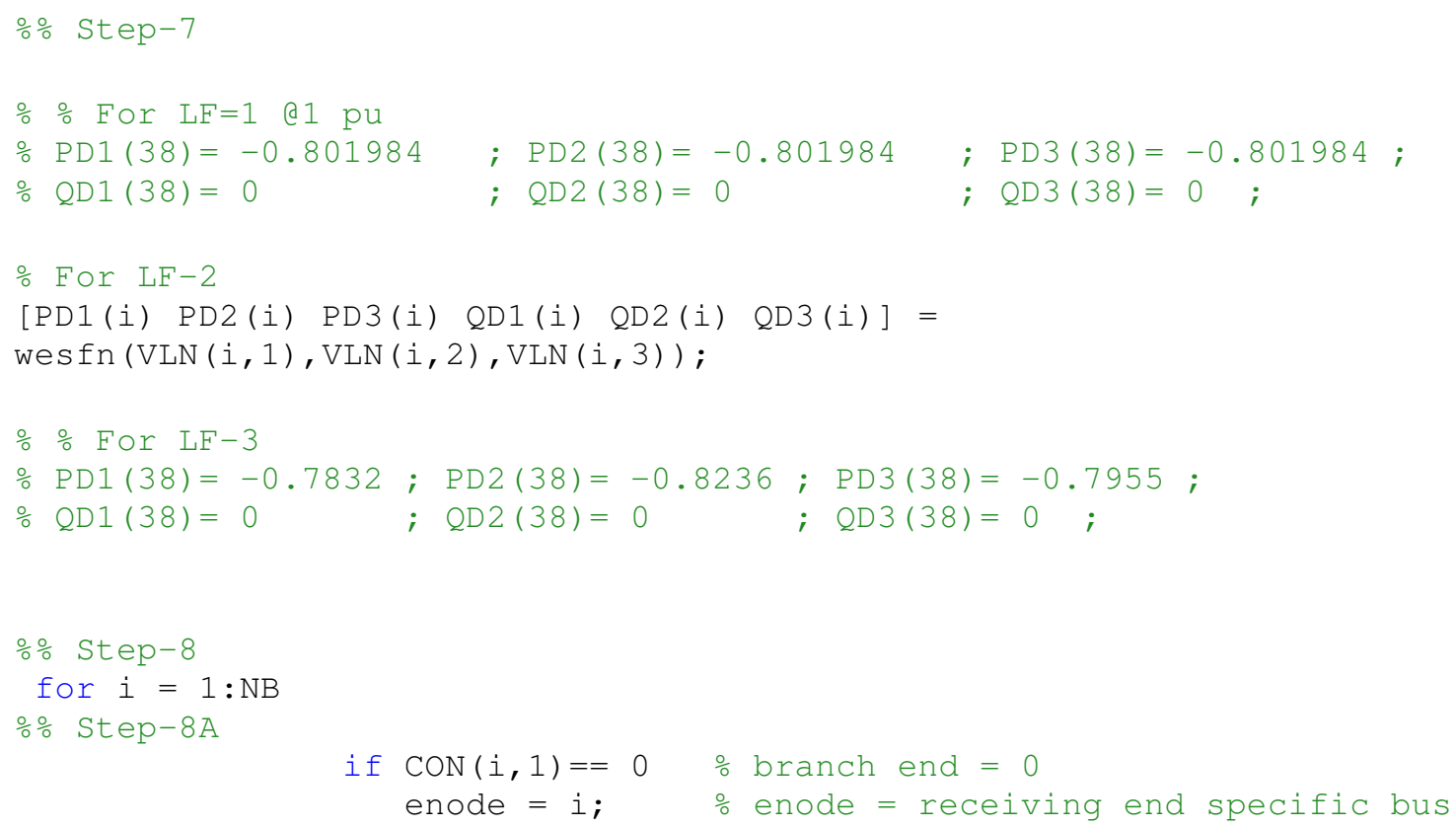

IBL (enode, $1: 3)=$ [AIBL (enode, 1$){ }^{*} \operatorname{complex}(\cos (\operatorname{angle}($ IBL (enode, 1$)))$, sin (angle (IBL ( enode, 1))) ) ...

AIBL (enode, 2) * complex (cos (angle (IBL (enode, 2))), sin (angle (IBL (enode, 2))) ) ...

AIBL (enode, 3) * complex (cos (angle (IBL (enode, 3))), sin (angle (IBL (enode, 3)) )) ] ; case 003

IBL $($ enode $, 1: 3)=[\operatorname{VLL}($ enode, 1$) /$ ZB $($ enode, 1$)-$

VLL (enode, 3) / ZB (enode, 3) ... 


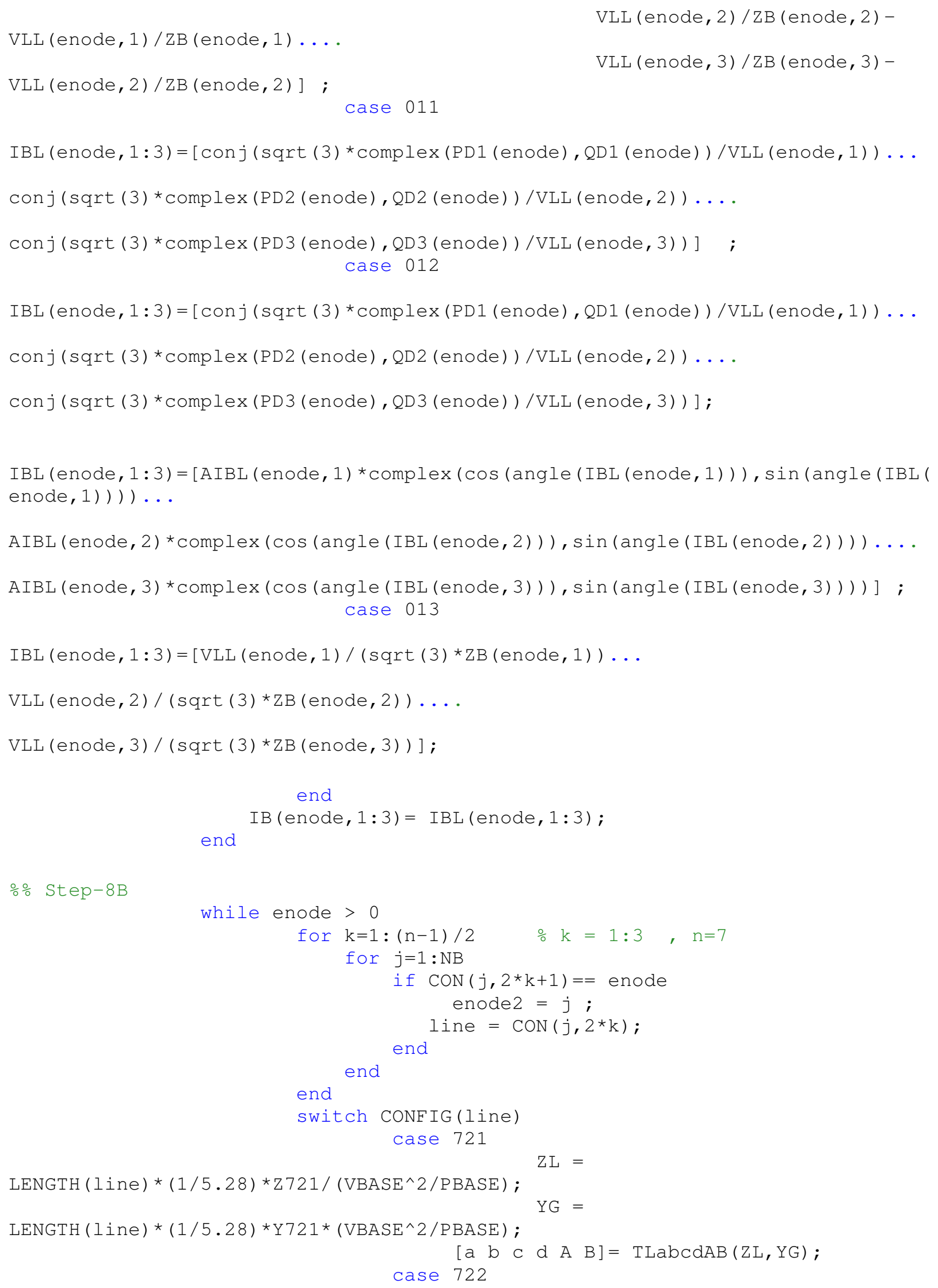




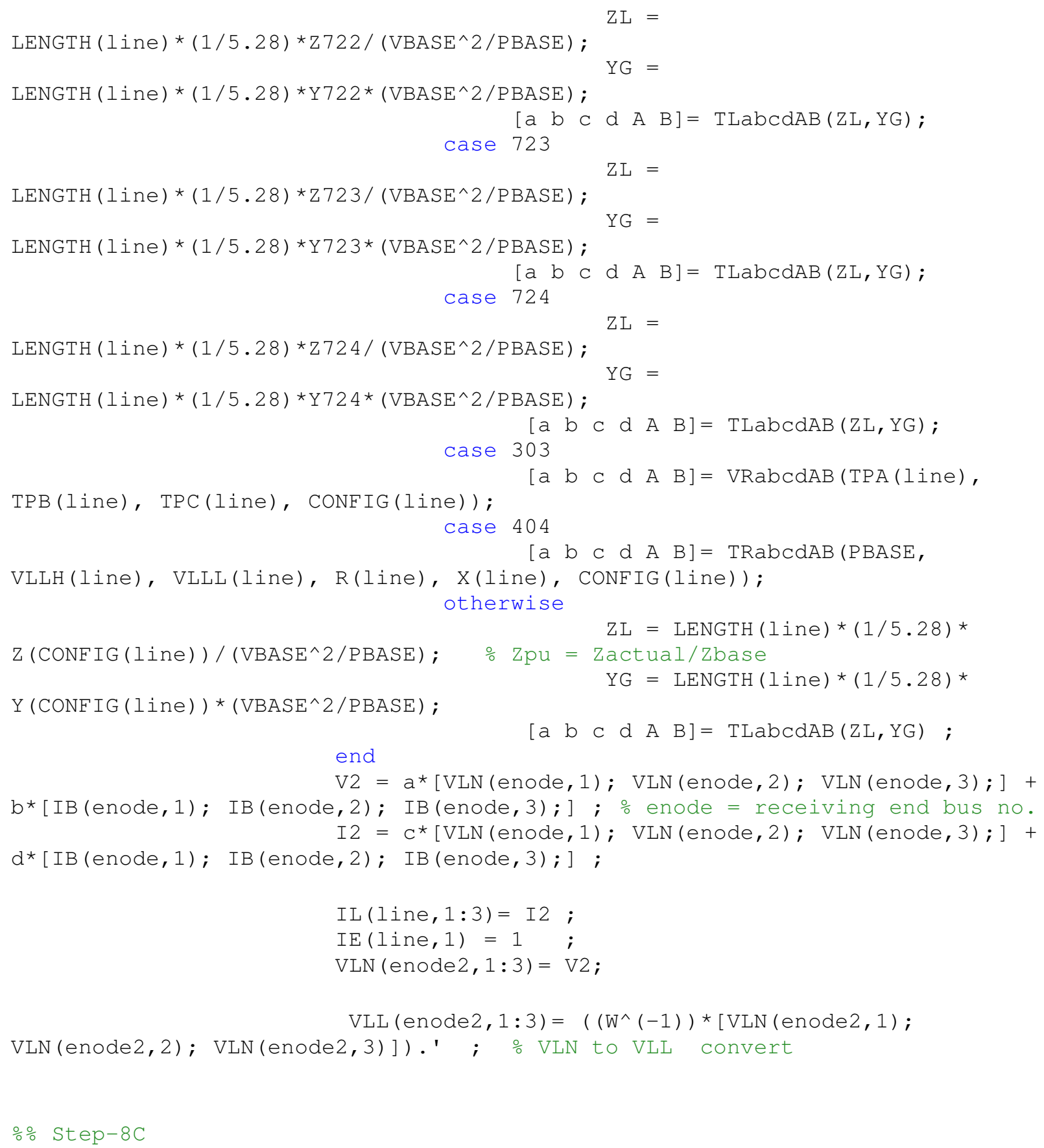


case 002

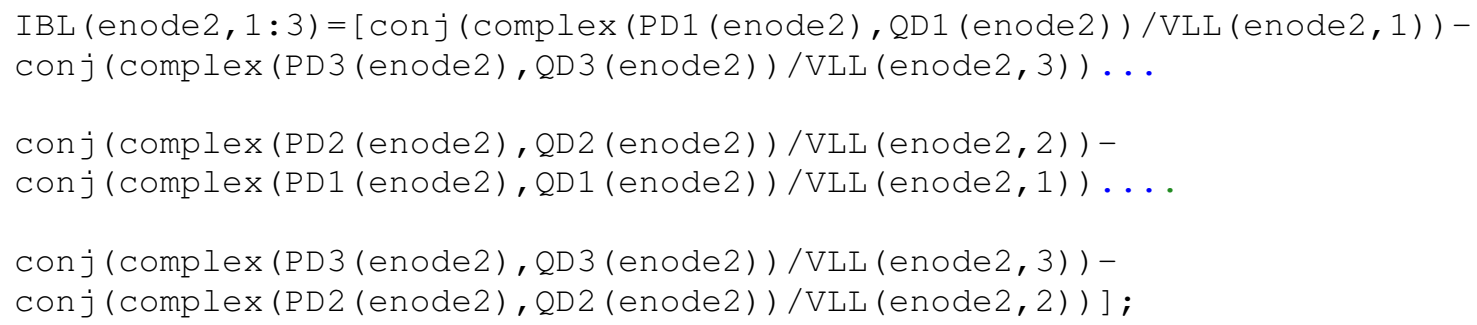




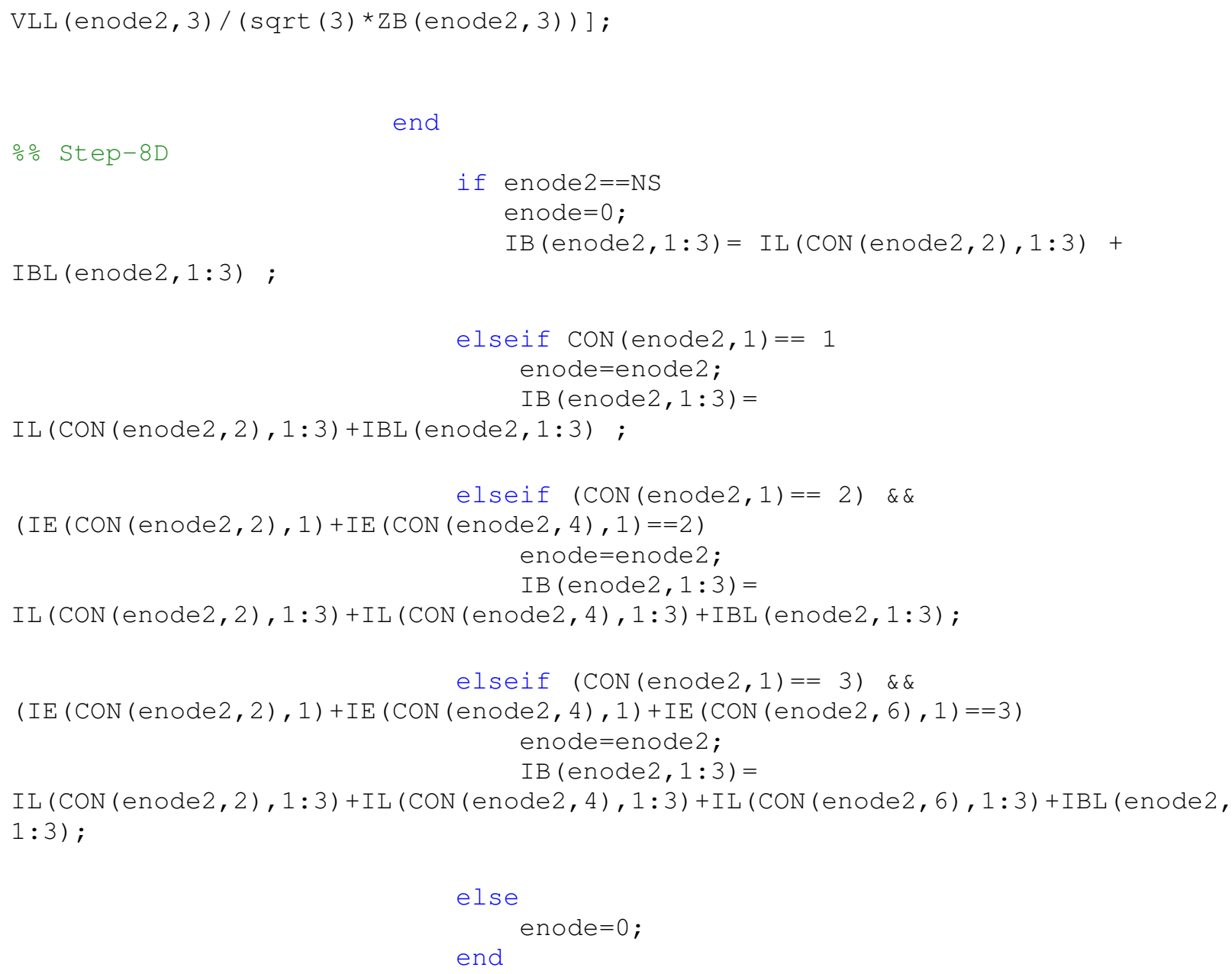

end

end

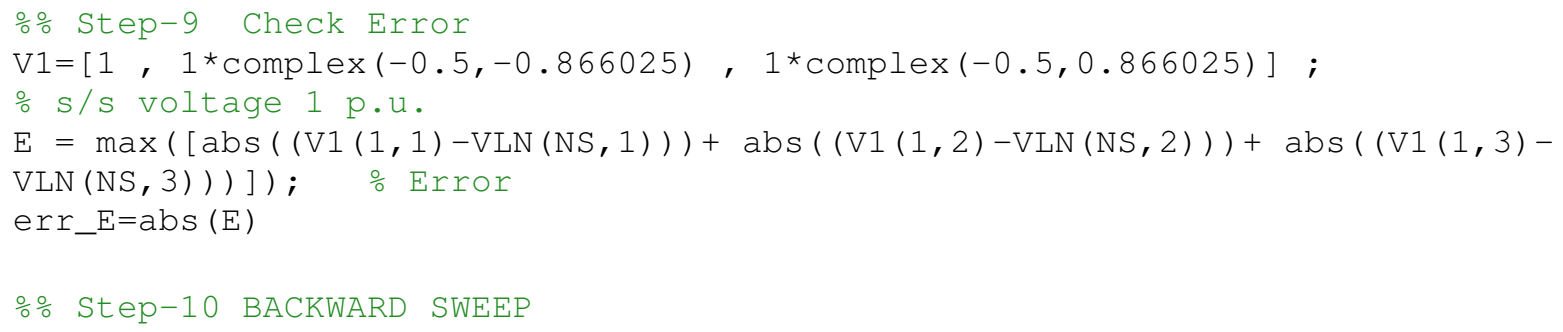




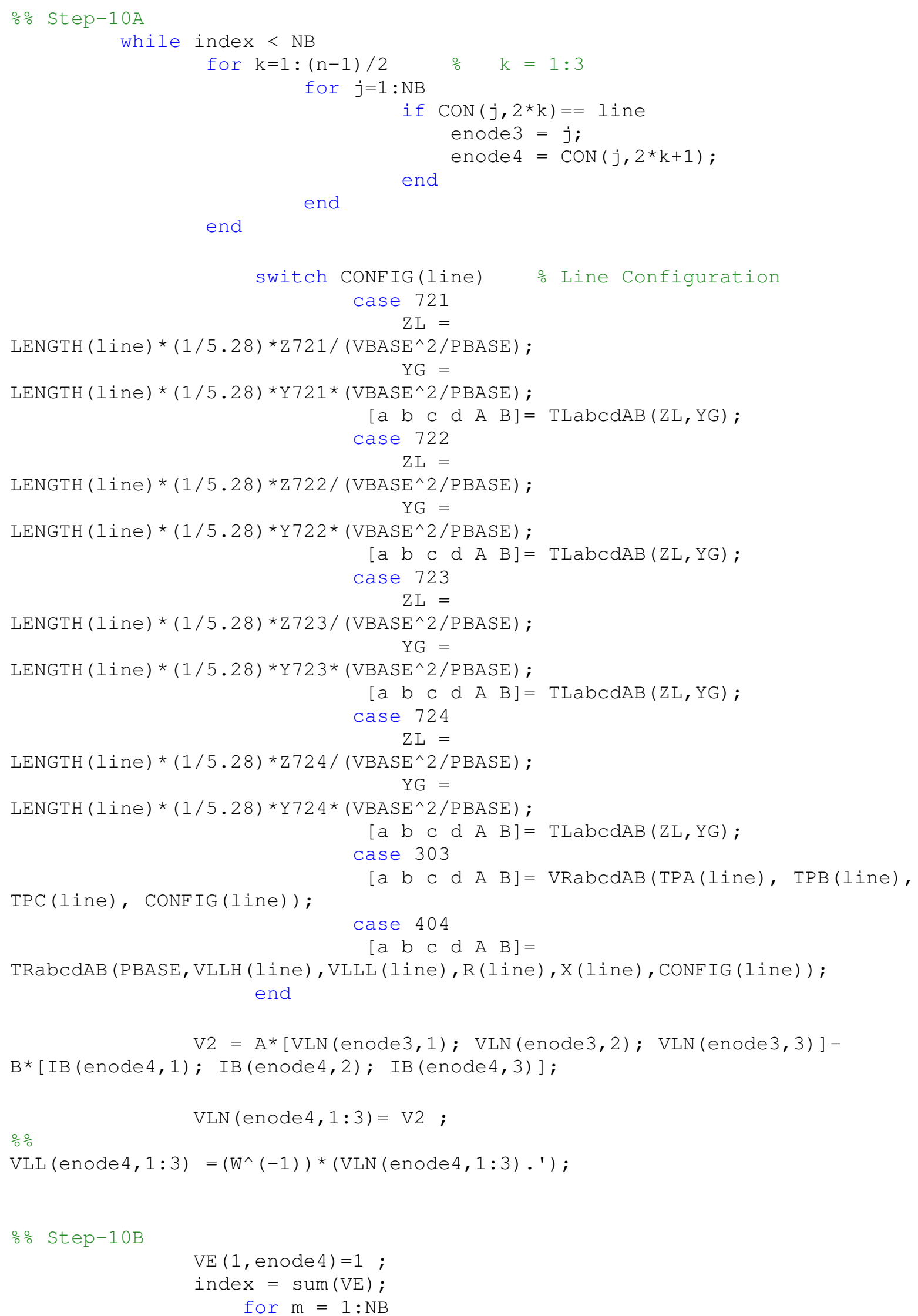




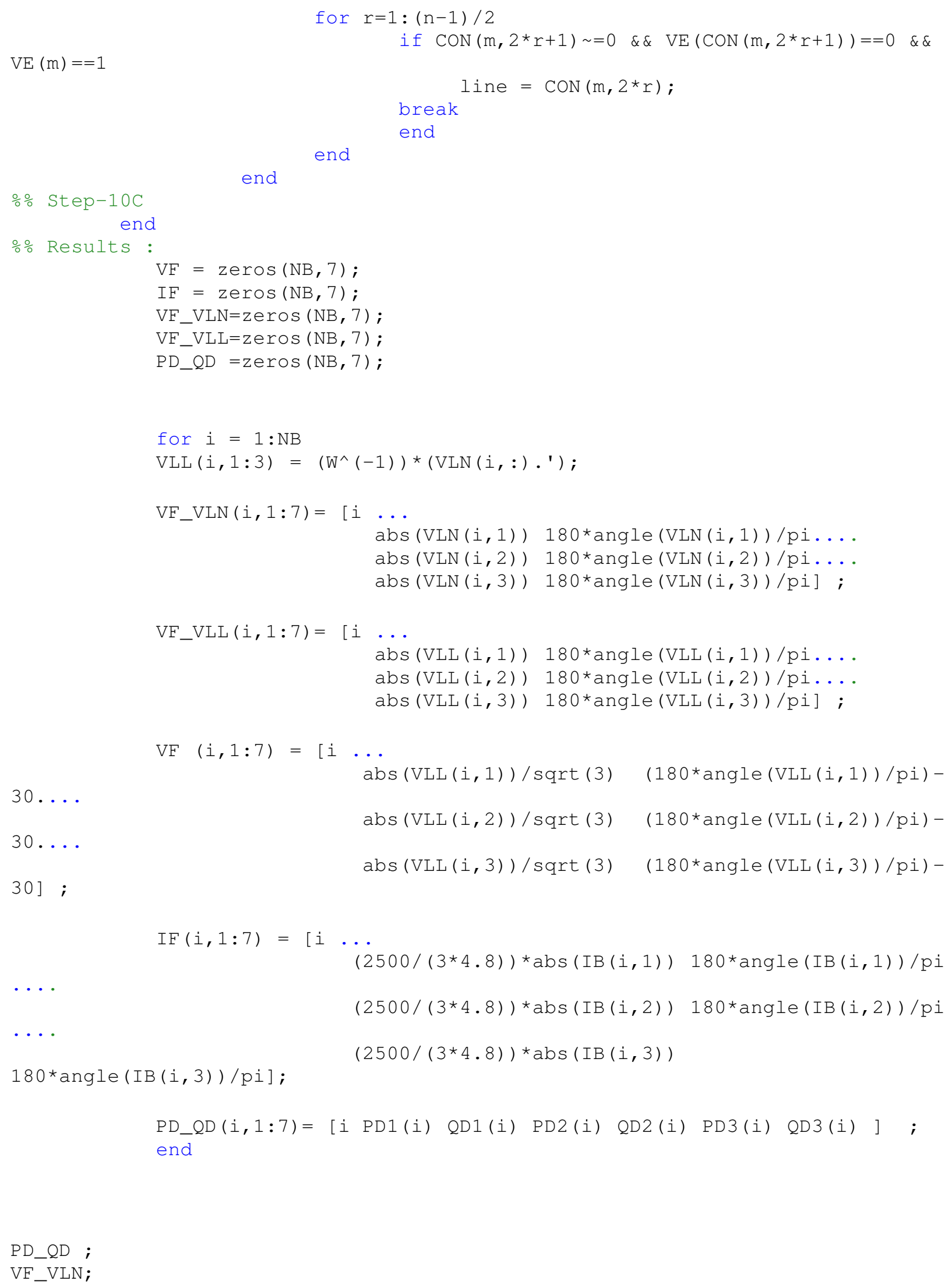


응 Step-11 Upgrade Iteration

$\mathrm{IT}=\mathrm{IT}+1$

end

응 Step-12 Solution

PD_QD

VLN_FINAL $=$ VF_VLN;

$\mathrm{VF}$ 


\section{Appendix E}

\section{MATLAB Code for Proposed Type 4 Model}

\section{Main Function File}

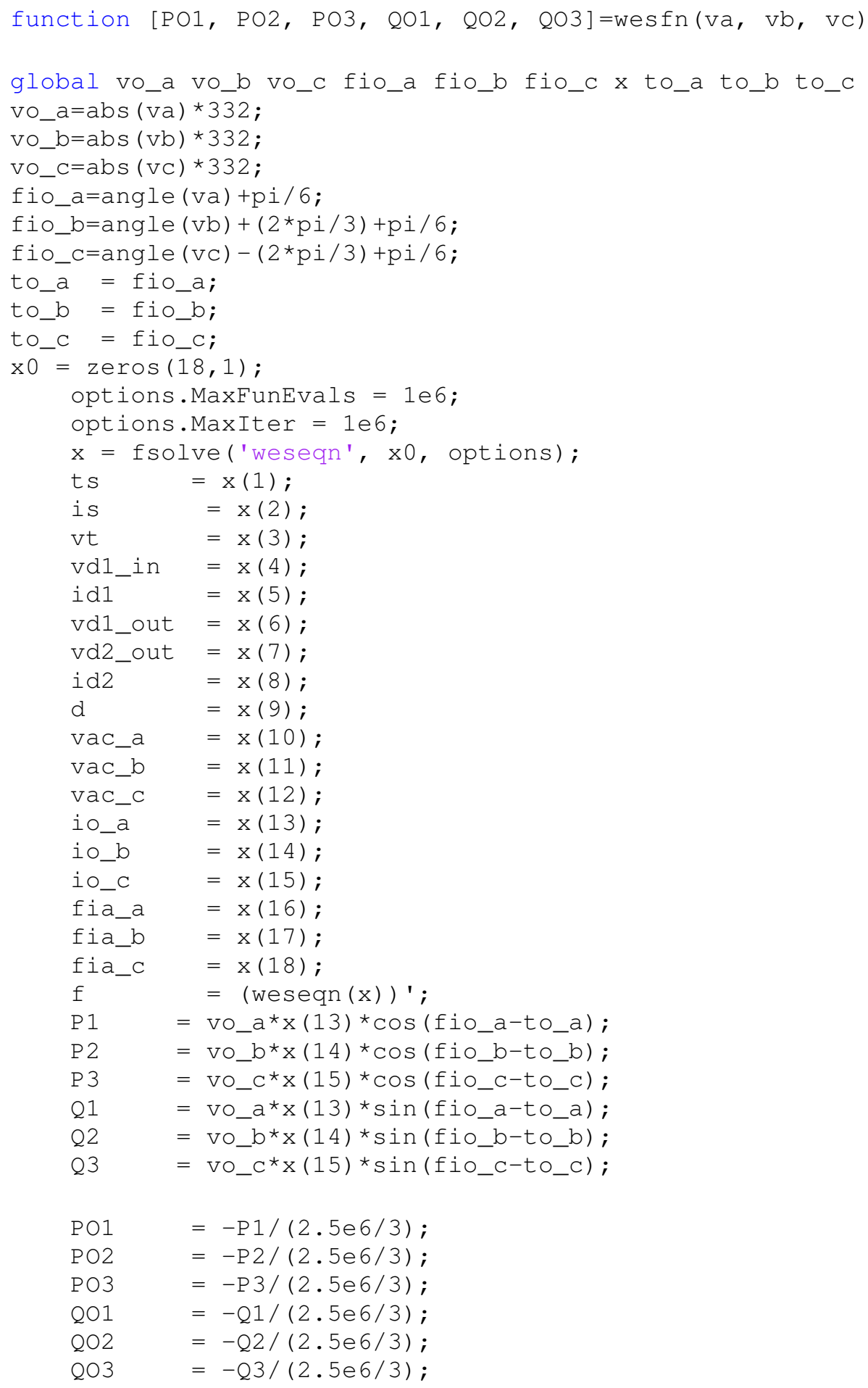


Display_PD_eD_pu $=[\mathrm{PO}, \mathrm{QO1}, \mathrm{PO} 2, \mathrm{QO2}, \mathrm{PO}$, $\mathrm{QO3}]$;

\section{System Equations}

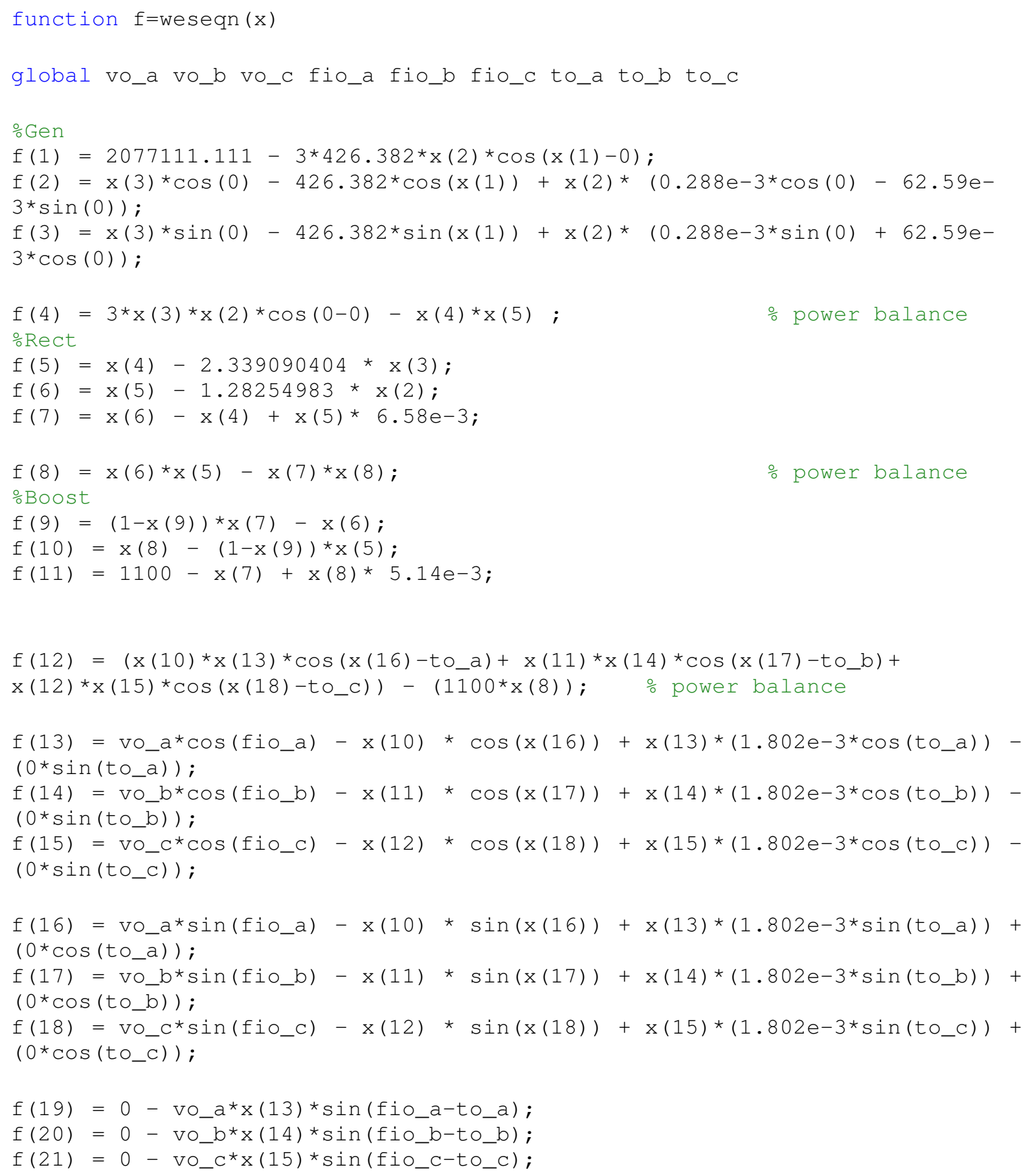

